\title{
Spontaneous Action Potential Activity and Synaptic Currents in the Embryonic Turtle Cerebral Cortex
}

\author{
Mark G. Blanton and Arnold R. Kriegstein \\ Department of Neurology and Neurological Sciences, Stanford University School of Medicine, Stanford, California 94305
}

We used loose-patch and whole-cell recording techniques to study the development of spontaneous action potential activity and spontaneous excitatory and inhibitory synaptic currents in embryonic neurons in the cerebral hemispheres of turtles. Sporadic action potential activity appeared early in development at stage 17, soon after morphologically identifiable pyramidal and nonpyramidal neurons were first observed in the cortex. As the cortical plate matured in midembryonic stages, action potential activity became more regular and fell into one of two distinct patterns, tonic and intermittent high-frequency firing.

Spontaneous excitatory and inhibitory postsynaptic currents (EPSCs and IPSCs) appeared at developmental stages 18 and 20, respectively, after action potential activity was established. EPSCs and IPSCs exhibited characteristic ionic dependence and pharmacology throughout development. EPSCs reversed in direction at the equilibrium potential for cations and were sensitive to 6-cyano-7-nitroquinoxaline2,3-dione, an antagonist of the non-NMDA type of glutamate receptor. IPSCs reversed at the equilibrium potential for chloride and were sensitive to bicuculline methiodide, a GABA $_{\mathrm{A}}$ receptor antagonist.

Spontaneous synaptic currents differed in their time course of development and in waveform parameters. Spontaneous EPSCs appeared at stage 18 and increased progressively in frequency, from $0.2 \pm 0.1 \mathrm{~Hz}$ at stage 20 to $3.2 \pm 2.0 \mathrm{~Hz}$ at stage 26 (hatching), while spontaneous IPSCs appeared at stage $\mathbf{2 0}$ and surpassed EPSCs in frequency, increasing to $7.1 \pm 1.6 \mathrm{~Hz}$ at stage 26. EPSCs exhibited stable amplitudes during development, with a mean conductance of 126 \pm 20 pS at stage 26, while IPSCs increased in mean amplitude, from $180 \pm 12 \mathrm{pS}$ at stage 18 to $260 \pm 44 \mathrm{pS}$ at stage 26. The rise time to peak conductance of both types of synaptic currents increased with developmental time, for EPSCs increasing from $1.5 \pm 0.5 \mathrm{msec}$ at stage 20 to $2.7 \pm 0.6 \mathrm{msec}$ at stage 26 and for IPSCs increasing from $2.9 \pm 0.2 \mathrm{msec}$ at stage 18 to $6.2 \pm 0.8 \mathrm{msec}$ at stage 26 . While the decay time constants increased for EPSCs, from $3.9 \pm 1.2 \mathrm{msec}$

\footnotetext{
Received May 3, 1991; revised July 19, 1991; accepted July 23, 1991.

We are indebted to Drs. John Huguenard, Jay Kadis, Paul Desan, and Istvan Mody for technical and statistical advice, and thank Drs. Mody, Huguenard, and Joseph LoTurco for helpful comments on the manuscript. We thank Dr. J. Dempster, University of Strathclyde, for generously making the SCAN software available. We also thank John Avilla and Isabel Parada for expert technical assistance. This research was supported by MSTP Training Grant GM07365 to M.G.B. and NIH Grant NS21223.

Correspondence should be addressed to Mark Blanton, Department of Neurology and Neurological Sciences, Stanford University Medical Center, Stanford, CA 94305.

Copyright (C) 1991 Society for Neuroscience $0270-6474 / 91 / 113907-17 \$ 05.00 / 0$
}

at stage 20 to $8.7 \pm 2.3 \mathrm{msec}$ at stage 26, decay time constants for IPSCs showed a decreasing trend from $24.0 \pm 5.2$ msec at stage 18 to $18.4 \pm 5.3 \mathrm{msec}$ at stage 26 . The excitatory and inhibitory synaptic currents were sensitive to the sodium channel blocker TTX and were thus dependent, in part, on spontaneous action potential activity. At midembryonic stages, EPSCs were reduced in frequency by TTX $(0.5 \pm 0.1$ to $0.1 \pm 0.1 \mathrm{~Hz}$ ), and IPSCs were substantially reduced in both frequency $(2.8 \pm 0.8$ to $0.3 \pm 0.1 \mathrm{~Hz})$ and amplitude (13.4 \pm 1.8 to $9.5 \pm 1.5 \mathrm{pA})$.

During the development of the cerebral cortex of turtles, spontaneous action potentials appeared first, followed by spontaneous excitatory synaptic currents, and then spontaneous inhibitory synaptic currents. The results provide information on the nature of the electrical signals generated by spontaneously active neurons and their synapses in developing cerebral cortex, and on the timing of expression of excitatory and inhibitory circuits. The timing of onset of physiological activity determines when mechanisms of synaptic competition and other activity-dependent processes can operate in the developing cerebral cortex.

Cortical neurons in turtles express receptors for amino acid neurotransmitters early in their differentiation (Blanton et al., 1990; M. G. Blanton and A. R. Kriegstein, unpublished observations), and the amino acids glutamate and GABA are also present at these early stages (Kriegstein et al., 1988; Blanton and Kriegstein, 1991a,b). Neurotransmitter-mediated intercellular communication can function prior to synapse formation, as it has been shown that an endogenous neurotransmitter activates glutamate receptors of the NMDA type on cortical cells soon after their generation (Blanton et al., 1990). This receptor activation may serve as a local mechanism for shaping neurite outgrowth, differentiation, and neuronal survival (Aruffo et al., 1987; Pearce et al., 1987; Balázs et al., 1988; Mattson et al., 1988). With the subsequent onset of action potential (AP) activity, axon elaboration, and synapse formation, a new array of potential developmental interactions emerges that may be critical in shaping neural circuits.

Neuronal firing and synaptic activity are involved in refining the organization of neural representations of sensory space and other functional maps (Reh and Constantine-Paton, 1985; Kleinschmidt et al., 1987; Shatz and Stryker, 1988). Spontaneous neuronal activity can also influence local circuits between individual cortical cells, as indicated by the alteration of cortical excitability produced by reversible pharmacologic suppression of neuronal activity (Furshpan and Potter, 1989; Segal and Furshpan, 1990; P. H. Desan, personal communication; see also 
Figure 1. A series of differentiating pyramidal neurons in the cerebral cortex of embryonic turtles, based on labeling of single cells by HRP (see Blanton and Kriegstein, 1991a), provides a time line for comparison with emerging physiological function. Pyramidal neurons form a single row of cells at the surface of the ventricular zone and have begun to claborate dendrites and projecting axons at stage 16 . A loose cortical plate is present by stage 19 , populated primarily by pyramidal neurons, and by stage 22 , the cortical plate has condensed to form a recognizable cellular layer $(C L)$. Afferents and recurrent collaterals to pyramidal dendrites are concentrated mainly in the molecular layer $(M L)$, which expands greatly as synapse formation proceeds during embryonic life, reflected in the increasing spine density on dendrites from stage 19 to the time of hatching at stage 26 . Axons of pyramidal cells descend into the subcellular layer $(S L)$ and give rise to recurrent branches that ascend into $M L$. The ventricular surface of the cortex is lined by a layer of ependymal glia somata $(E L)$.

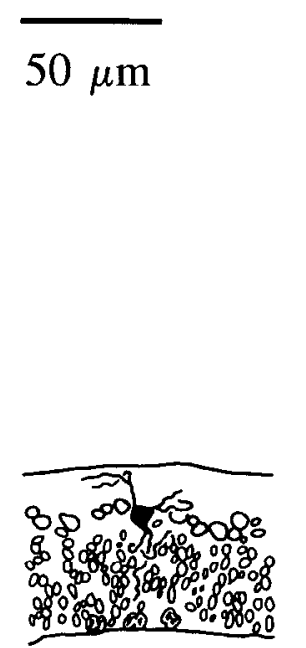

$$
\text { stage } 16
$$

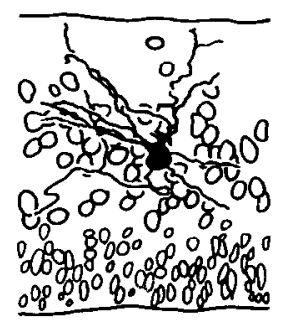

stage 19

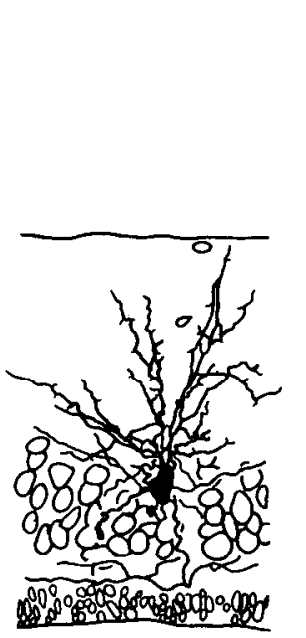

stage 22

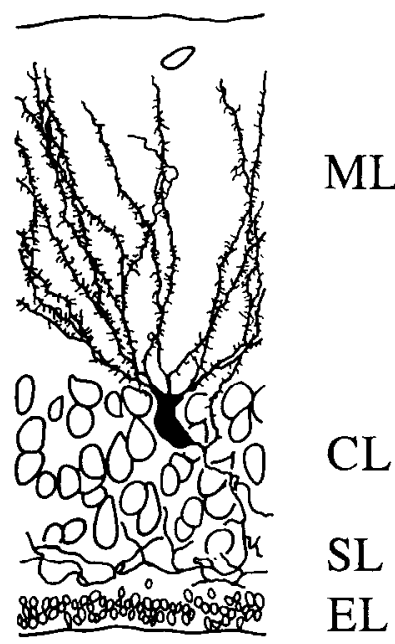

stage 26
Sur et al., 1990). In the formation of neural maps, activitydependent mechanisms are thought to select synapses that participate in depolarizing postsynaptic cells, stabilizing effective synapses, and eliminating ineffective synapses (Hebb, 1949; Stent, 1973). Under such a scheme, the interaction of synaptic inhibition and excitation will critically determine which synapses are selected (Bear et al., 1987).

As a first step in trying to understand how local circuits differentiate in the cerebral cortex and, in particular, how recurrent excitatory circuits with the potential for positive feedback form without yielding uncontrolled excitation, it is important to determine when spontaneous AP and synaptic activity arise during development. Availability of such information has been limited by the difficulty in oblaining stable physiological recordings from fragile young neurons. However, this difficulty has been removed by the application of the extracellular loose-patch technique (Forda et al., 1982; Jackson et al., 1982) for studying AP activity and by application of whole-cell recording in intact embryonic cortex (Blanton et al., 1989) for analysis of synaptic currents.

The analysis of physiological development is facilitated by use of the embryonic dorsal cerebral cortex of the turtle, in which profound resistance to anoxia (Belkin, 1963) allows large portions of the CNS to be studied intact, increasing the likelihood of sampling normal spontaneous activity patterns in vitro. Studies on the morphological differentiation of the principal neuronal cell types of the turtle cerebral cortex, the pyramidal and nonpyramidal neurons, indicate that, like their counterparts in mammalian neocortex, these cell types in turtles can be distinguished early in development and differentiate in parallel (Goffinet, 1983; Blanton and Kriegstein, 1991a). We therefore used loose-patch and whole-cell techniques to study the appearance and differentiation of spontaneous AP activity and of spontaneous excitatory and inhibitory synaptic currents in cortical neurons of embryonic turtles.

\section{Materials and Methods}

Experimental preparation. Embryonic red-eared turtles (Pseudemys scripta, from Tangi Turtles, Ponchatoula, LA) were used in this study. We used external morphologic criteria (Yntema, 1968) to place embryos sclcctcd for study into stages, with stage 15 corrcsponding to the bcginning of neurogenesis (Goffinet et al., 1986), and stage 26, to hatching. The cerebral cortex of turtles is composed of longitudinal cortical zones running rostrocaudally that may correspond to the cardinal divisions of the mammalian cerebrum: the paleocortex, neocortex, and archicortex (Desan, 1988). Dorsal cortex, with connections similar to primary sensory and polysensory association cortex, was identified in young embryos by its location dorsal to the lateral ventricle, flanked by lateral olfactory and medial hippocampal cortices. Pyramidal and nonpyramidal neurons in cortex can be distinguished as early as stage 15 , due to their characteristic morphological features (Blanton and Kriegstein, 1991a). The data presented here come almost exclusively from pyramidal neurons, which occupy a single cell-dense layer (Fig. 1). These cells send long axonal branches to distant targets as early as stage 16 and give rise to recurrent collateral branches that became increasingly dense at stages 19 and 20 (Blanton and Kriegstein, 1991a).

Turtle eggs were maintained in an incubator at $30^{\circ} \mathrm{C}$, until selected for use. After removal from the egg, the embryo was anesthetized with hypothermia, according to Stanford University guidelines for the care and use of laboratory animals. Each embryo was staged according to external morphologic criteria that correlate with developmental time (Yntema, 1968) and brain morphological maturation (Blanton and Kriegstein, 1991a). The brain was removed, and incisions were made in the cerebral hemispheres at rostral and caudal levels and the septum, allowing the cerebral cortex to be flattened, ventricular side up. Alternatively, coronal slices $(400 \mu \mathrm{m})$ were obtained with standard methods, as described previously (Blanton et al., 1989). The tissue was stabilized in Petri dishes using a fibrin clot, and the Petri dishes were positioned on the stage of an upright Leitz microscope (Blanton et al., 1989). The preparation was superfused with oxygenated turtle Ringer's $(1-1.5 \mathrm{ml} /$ min at $22-24^{\circ} \mathrm{C}$ ), containing (in $\mathrm{mM}$ ) $\mathrm{NaCl}, 96.5 ; \mathrm{KCl}, 2.6 ; \mathrm{CaCl}_{2}, 2$; $\mathrm{MgCl}_{2}, 2 ; \mathrm{NaHCO}_{3}, 31.5$; and dextrose, 10 .

Loose-patch recording. Loose-patch clamp recordings were obtained from slices and slabs of embryonic cortex by modifying a previously described technique (Forda et al., 1982; Jackson et al., 1982; see also Coleman and Miller, 1989). Electrodes were fashioned from borosilicate glass (World Precision Instruments, New Haven, CT) using a Kopf vertical puller. A single-stage pull was used to produce pipettes with 
long taper and tip resistances of 2-5 M . The electrodes were filled with turtle Ringer's. To obtain recordings, electrodes were lowered into the tissue while positive pressure was applied through the pipette tip using a $10 \mathrm{ml}$ syringe connected to the pipette holder. The amplitude of currents elicited by brief voltage steps $(1 \mathrm{mV}, 10 \mathrm{msec}, 5 \mathrm{~Hz})$ was monitored as the electrode was advanced. Upon noting a decrease in current (reflecting a resistance increase as a cell was approached), the pressure was reversed at the pipette tip by applying mild suction through the syringe. Seal resistances in the subgigaohm range (50-500 M $)$ were obtained, and recordings were maintained stably for up to several hours.

Currents generated by spontaneous action potential activity were accepted for analysis if the activity was clearly resolved and remained stable for at least $15 \mathrm{~min}$. Cells that accelerated in rate or decreased noticeably in amplitude during the recording were rejected. The current data, obtained using an Axopatch IIA (Axon Instruments, Burlingame, CA) and a List EPC-7, were recorded in digital form on magnetic tape for off-line analysis. Current waveform parameters were measured manually on a Tectronix digital oscilloscope. Firing patterns were analyzed using SPKHIST software that bins spike frequency for interval histograms (written by J. Kadis, Stanford University) and by inspection of chart records.

Whole-cell recording. For analysis of spontaneous synaptic currents, whole-cell recordings were obtained from embryonic neurons in intact cerebral hemispheres, as previously described (Blanton et al., 1989). Patch electrodes were filled with a solution containing (in $\mathrm{mM}$ ) Csgluconate, 122; $\mathrm{CaCl}_{2}, 0.9 ; \mathrm{MgCl}_{2}, 0.9$; HEPES, 9; EGTA, 10; brought to $\mathrm{pH} 7.3$ using $1 \mathrm{~N} \mathrm{HCl}$ (adding approximately $2 \mathrm{~mm} \mathrm{Cl}^{-}$to the solution). The calculated equilibrium potential for chloride $\left(E_{\mathrm{Cl}}\right)$ was -74 $\mathrm{mV}$ and for cations $\left(E_{\mathrm{cos}}\right)$ was $0 \mathrm{mV}$. In most experiments, $1-2 \%$ biocytin (Horikawa and Armstrong, 1988) was added to the pipette to allow morphological identification of recorded cells (Blanton et al., 1990; LoTurco et al., 1990). The osmolarity of the solution was between 260 and 280 mOsm.

Patch electrodes had tip resistances of 3-7 M . Series resistance was estimated by observing the calibrated control dial on the amplifier after series resistance and capacitance compensation were completed. Series resistance $\left(R_{s}\right)$ values were less than $20 \mathrm{M} \Omega$, leading to minimal voltage error with the small currents recorded here $(2 \mathrm{mV}$ for a $100 \mathrm{pA}$ current at $R_{s}=20 \mathrm{M} \Omega$ ).

Neurons were identified by resting potentials of -50 to $-70 \mathrm{mV}$ in current clamp, high input impedances $(>300 \mathrm{M} \Omega$ ), active conductances, and after processing for biocytin, by their neuronal morphology. Glial cells, identified morphologically, exhibited distinctly different physiological properties, including more negative resting potentials and lower input impedances than neurons, and the absence of active conductances (Connors and Ransom, 1987; Blanton et al., 1990). All of the data presented here came from morphologically identified pyramidal neurons, except where indicated explicitly as coming from nonpyramidal cells.

Currents were recorded using a List EPC-7 patch-clamp amplifier, and the data, filtered at $3 \mathrm{kHz}$, were digitized and stored on tape for off-line analysis. Spontaneous synaptic currents, recognized by their rapid rise to peak and exponential decay, were analyzed using SCAN software provided by Dr. J. Dempster, University of Strathclyde. A software selectable threshold was set that allowed acquisition of spontaneous currents exceeding baseline noise in amplitude. In relatively mature animals, from 300 to 400 events were acquired for each cell. In the youngest animals, in which the frequency of synaptic events was very low, as few as 50 events were obtained for excitatory currents. For inhibitory currents in animals younger than stage 20 , at least five synaptic currents were recorded for each cell, and these currents were observed in nearly all cases only if the thalamocortical axons were stimulated.

Current amplitudes, rise times to peak (time from baseline to peak current), and decay time constants ( $\tau$-values) were measured, and histograms were constructed using SCAN. The acquired currents were also averaged, and the same parameters were measured on the averaged current sweeps. The mean values for each parameter indicated by the population histograms were found to be the same as the values obtained for the averaged traces; the data reported here are the values from the averaged traces. The frequency of synaptic events was determined from chart recordings with an expanded time base. The number of synaptic events occurring in representative $100 \mathrm{sec}$ epochs were counted to obtain the frequency information.

The measured values for synaptic current parameters were compared for various embryonic stages using one-way ANOVA, with the aid of STATVIEW SE + software on a Macintosh computer. For parameters with statistically significant developmental differences, post hoc Scheffé $F$ tests were performed for all pairwise combinations of stages represented in the sample. For data compared between two groups within a stage (e.g., pre- and post-TTX at stage 21), a two-tailed Student's $t$ test was used.

The currents were characterized pharmacologically by adding antagonists to the bathing medium. Antagonists used included bicuculline methiodine (BMI; 5-20 $\mu \mathrm{M}$ ), 6-cyano-7-nitroquinoxaline-2,3-dione (CNQX; 2-10 $\mu \mathrm{M}$ ), and tetrodotoxin (TTX; 0.5-1 $\mu \mathrm{M}$ ). Drugs were obtained from Sigma (BMI), Cambridge Research Biochemicals (CNQX), and Calbiochem (TTX). Micropipettes for pressure ejecting $\gamma$-aminobutyric acid (GABA; $1 \mathrm{mM}$ ) were used in some loose-patch experiments (see Blanton et al., 1990). A bipolar stimulating electrode (tungsten microelectrodes, Frederick Haer) was mounted directly on the adapter holding the Petri dish and was used to stimulate thalamocortical or intracortical axons.

\section{Results}

\section{Appearance of AP activity}

Spontaneous AP activity was present in loose-patch recordings from embryonic cortical neurons beginning at stage 17 , soon after the first neurons appeared in the cortex (see Fig. 1). Data were obtained from 285 units. Recorded biphasic capacitance transients corresponding to action potentials (Forda et al., 1982; Jackson et al., 1982; referred to here as AP activity) were clearly resolved above the baseline noise. The initial inward transient is referred to here as phase 1 and is followed by an outward transient, phase 2 . The biphasic transients were of similar amplitudes through development (stage 17, $50 \pm 12 \mathrm{pA}, n=8$; stage $20,59 \pm 28 \mathrm{pA}, n=20$; stage $23,60 \pm 25 \mathrm{pA}, n=17$; measured for phase 1 ; see Table 1 for details and statistics). While baseline noise levels were affected by seal resistance, the pattern and waveform of spontaneous AP activity were independent of this value. Spontaneous activity was unchanged during formation and release of patch electrode seals on neurons, indicating that activity did not result merely from stimulation by the patch electrode or from neuronal injury. Moreover, conventional extracellular microelectrode recordings revealed similar AP activity (P. H. Desan and A. R. Kriegstein, unpublished observations).

At the earliest age studied, stage 16 , no spontaneous singleunit activity was detected in four preparations, although in two recordings very brief outward events $(<0.2 \mathrm{msec})$ were observed that may correspond to APs of extrinsic afferents (see Huttenlocher, 1967; Mountcastle et al., 1969). Extracellular AP transients could be evoked in cells that lacked spontaneous activity by applying depolarizing voltage steps in the loose-patch configuration ( $n=3$; see Fig. $2 A$ ). APs could also be elicited in these cells with depolarizing current pulses in whole-cell recordings in current-clamp mode (Fig. $2 B$ ). These APs could be blocked by the sodium channel blocker TTX ( $1 \mu \mathrm{M}$; not shown).

Spontaneously active units with biphasic waveforms were detected at stage 17 (Fig. 3). Units typically fired APs tonically at a low rate $(0.43 \pm 0.3 \mathrm{~Hz}$, mean $\pm \mathrm{SD} ; n=16)$, often separated by periods of silence of greater than 1 min duration $(9$ of 19 units). APs immediately following quiet periods were often grouped in clusters. These data indicate the sporadic nature of early appearing AP activity. Similar tonically active units were found throughout development and in mature animals, but quite periods were less frequent with maturation ( 1 of 17 at stage 19 , 4 of 19 at stage 20). The firing rate of tonically active units showed an increasing trend from $0.43 \pm 0.3 \mathrm{~Hz}$ at stage $17(n$ 


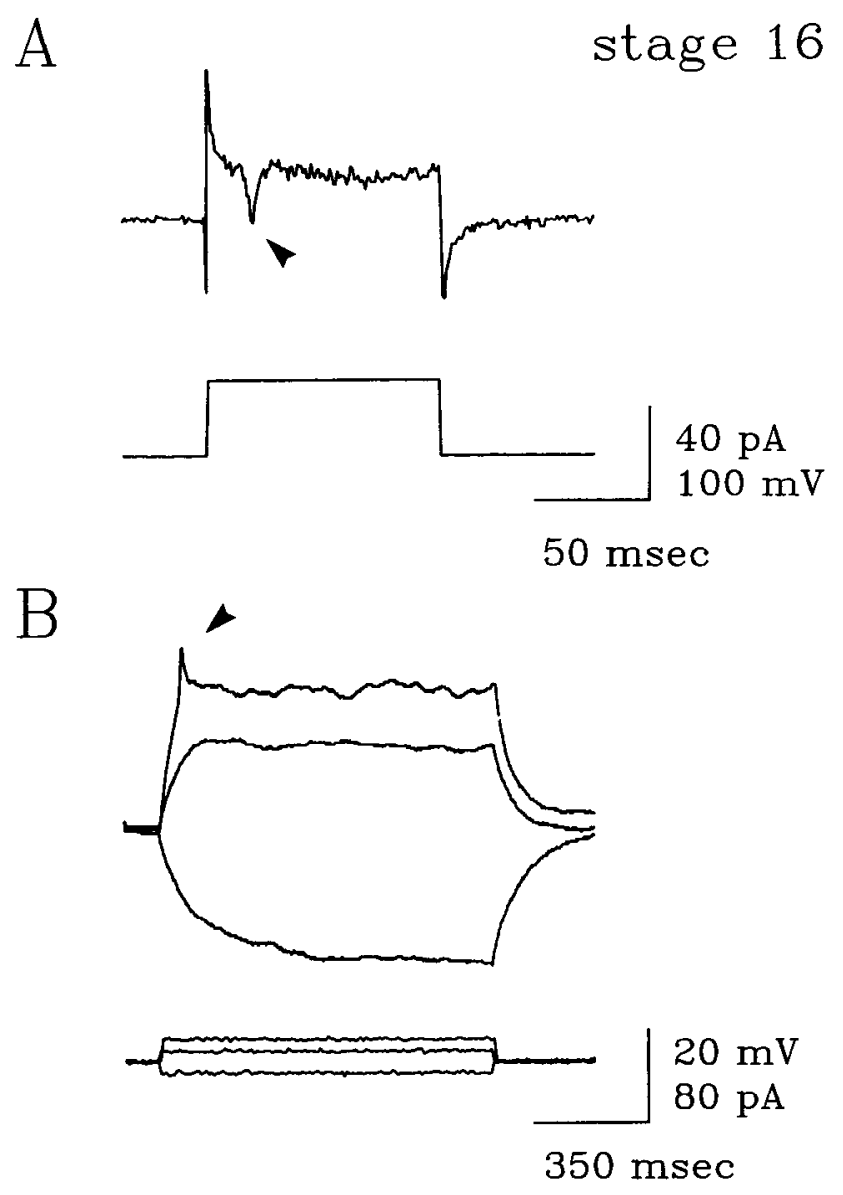

Figure 2. Young cortical neurons at stage 16 are not spontaneously active but can fire APs when depolarized. $A$, Application of a depolarizing voltage step (lower trace) to a loose patch activates a current transient (arrowhead in upper trace) in a recording in which no spontaneous APs were detected during an $8 \mathrm{~min}$ period. $B$, Gigaseal formation on a quiescent cell allowed a whole-cell recording to be obtained. A depolarizing current pulse in current clamp (lower traces) produced a broad AP (arrowhead in upper trace; $16 \mathrm{msec}$ at half-amplitude); a subthreshold depolarization is also shown. A hyperpolarizing current pulsc produced a hyperpolarizing response, illustrating the long time constant of the embryonic neuron.

$=16)$ and $0.63 \pm 0.61$ at stage $19(n=9)$ to $1.38 \pm 0.57$ at stage $20-21(n=8)$ and $1.32 \pm 0.47$ at stage $23(n=10)$.

Another type of unit intermittently fired repetitive APs at frequencies greater than $50 \mathrm{~Hz}$ and could also fire tonically. Because activity from multiple units could be resolved simultaneously, possibly by trapping a process of a second cell in the seal (Forda et al., 1982), the activity of adjacent neurons could be compared directly. As early as stage 20 , distinct activity patterns were noted in simultaneously recorded units (Fig. 4). When the AP waveforms were analyzed, the intermittent highfrequency unit always had a faster waveform than the tonically firing unit. This distinction was preserved throughout development. When interspike interval histograms were generated from such pairs, the interval distributions differed for fast and slow waveform units into adulthood (Fig. 5).

The slow, tonically firing and fast, intermittent-repetitively firing units may correspond to pyramidal and nonpyramidal cell types, respectively. Studies in mature turtles indicate that pyramidal cells fire APs that are broader than those of nonpyr-

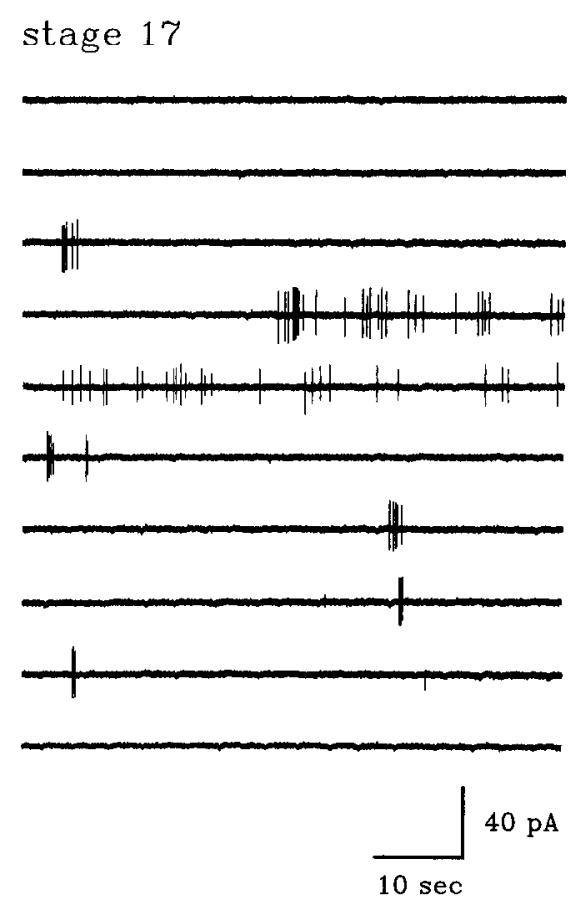

Figure 3. Periodic spontaneous AP activity in a stage 17 cortical neuron. Loose-patch current traces from a continuous recording show clearly resolved sporadic activity separated by long quiet periods. Activity, when present, was often grouped in clusters.

amidal cells (Connors and Kriegstein, 1986; see Connors and Gutnick, 1990, for review). The two firing patterns likely represent different cell types rather than two cells of the same type that differ in maturation. First, the relationship of waveform to firing properties was preserved throughout development. Second, whilc tonic unit waveforms decreased in duration during development, these waveform durations were longer than those of repetitively firing units throughout development (see Table 1). Third, recordings from coronal slices to allow identification of recording sites showed that only fast waveform units were found in the marginal zone, and these units were also common in the subcellular layer, zones in which nonpyramidal cells are common (Connors and Kriegstein, 1986; Blanton et al., 1987). Fourth, when gigaseals were formed with slow waveform neurons and the membrane patch ruptured to make whole-cell recordings, biocytin labeling revealed cells with pyramidal morphology.

In mature turtle cortex, nonpyramidal neurons have been shown to mediate feed-forward GABAergic inhibition (Connors and Kriegstein, 1986; Kriegstein and Connors, 1986). The patterns of unit activity in embryonic cortex indicate that fast waveform units in developing cortex could also mediate GABAcrgic inhibition. At stage 20, focal GABA application (1 mM) and afferent stimulation transiently block spontaneous activity of slow waveform units (Fig. 6). Repetitive bursts of fast waveform unit activity, likely to represent activity of inhibitory nonpyramidal neurons, are correlated with a transient suppression of firing by nearby tonic units, likely pyramidal neurons, resembling the pattern in mature turtle cortex (Kriegstein and Connors, 1986). The suppression was observed in four different recordings, occurring at least five times in each.

These results indicate that cortical neurons begin to fire spon- 


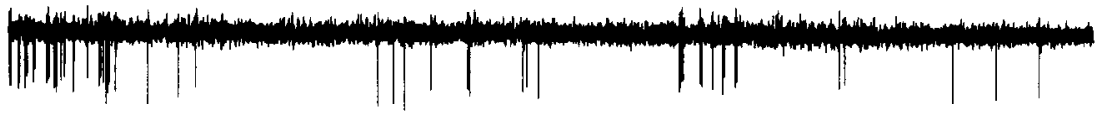

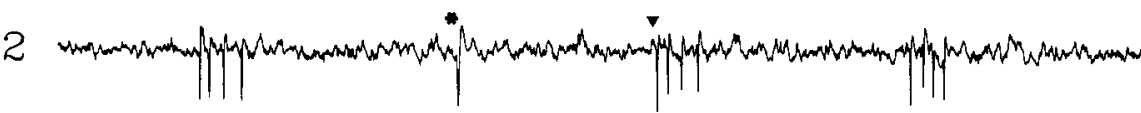

3
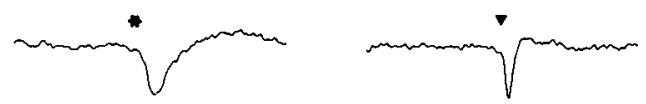

B stage 23

1

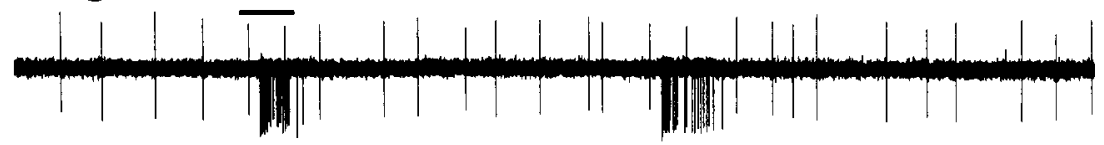

2

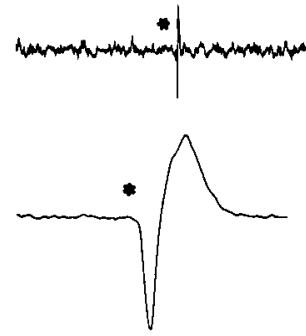

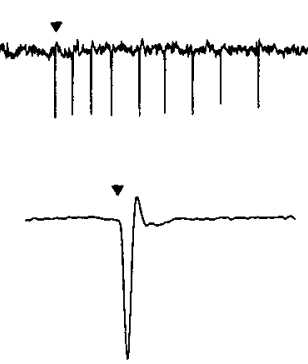
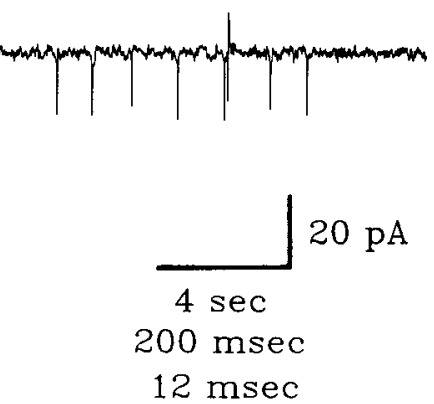

Figure 4. Distinct firing patterns and waveforms of spontaneously active units in embryonic cortex. Recordings from stages $20(A)$ and $23(B)$ embryos containing two units with distinct spontaneous firing patterns (horizontal bar in trace 1 marks portion expanded in trace 2 , and symbols denote individual units expanded below in trace 3). Units that fire single APs tonically (asterisks) exhibit a slower waveform than do those that fire repetitively (arrowheads) as early as stage 20 and throughout embryonic development. As development proceeds, fast units become capable of more sustained repetitive firing. taneous APs early in development, sporadically at first but soon falling into one of two distinctive patterns. Slow waveform, tonically active neurons, likely pyramidal neurons, and fast waveform, repetitively firing neurons, likely nonpyramidal neurons, both therefore contribute to spontaneous activity in developing embryonic cortex.

\section{Spontaneous excitatory and inhibitory synaptic currents}

Spontaneous synaptic currents with rapid rise and slow exponential decay were observed in embryonic neurons beginning at stage 18 , and by stage 20 , two types of synaptic currents could be distinguished based on differing reversal potentials. One type

\begin{tabular}{|c|c|c|c|c|c|}
\hline \multirow[b]{2}{*}{ Stage } & \multicolumn{2}{|c|}{ Phase 1 duration (msec) } & \multicolumn{2}{|c|}{ Phase 2 duration (msec) } & \multirow{2}{*}{$\begin{array}{l}\text { Phase } 1 \text { amplitude } \\
\text { of tonic units } \\
\text { (pA) }\end{array}$} \\
\hline & Tonic units ${ }^{a}$ & Repetitive units ${ }^{b}$ & Tonic units ${ }^{c}$ & $\begin{array}{l}\text { Repetitive } \\
\text { units }^{d}\end{array}$ & \\
\hline 17 & $3.0 \pm 1.2(8)$ & - & $6.7 \pm 1.2(8)$ & - & $50.1 \pm 11.8(8)$ \\
\hline 20 & $3.4 \pm 1.0(20)^{*}$ & $1.2 \pm 0.3(3)^{*}$ & $8.9 \pm 2.3(20)$ & $4.1 \pm 3.9(3)$ & $59.4 \pm 28.5(20)$ \\
\hline 21 & $3.8 \pm 1.4(8)^{*}$ & $1.3 \pm 0.4(4)^{*}$ & $9.7 \pm 2.6(8)$ & $3.5 \pm 2.7(4)$ & \\
\hline 22 & $3.4 \pm 1.1(5)^{*}$ & $1.3 \pm 0.3(4)^{*}$ & $9.0 \pm 2.5(5)$ & $2.6 \pm 3.1(4)$ & \\
\hline 23 & $2.0 \pm 0.6(17)^{*}$ & $1.1 \pm 0.2(8)^{*}$ & $4.9 \pm 1.8(17)$ & $3.2 \pm 1.5(8)$ & $60.2 \pm 25.0(16)$ \\
\hline 24 & $1.6 \pm 0.3(9)^{*}$ & $1.1 \pm 0.2(4)^{*}$ & $4.3 \pm 1.6(9)$ & $2.0 \pm 1.8(4)$ & \\
\hline
\end{tabular}

Values shown are mean \pm population $\mathrm{SD}(n)$.

*, Two-tailed unpaired $t$ test indicated that phase 1 durations of loose-patch APs differed for tonic and repetitive units at all stages tested $(20-24)$ at the $p<0.05$ level or better.

"One-factor ANOVA indicated a significant developmental change in phase 1 duration, with $p=0.0001, F=10.75$, $\mathrm{df}=70$. A post hoc Scheffe $F$ test indicated that stages 17 and 22 differed from stage 24 at the $95 \%$ confidence level and stages 20 and 21 differed from stages 23 and 24 at the $99 \%$ level.

${ }^{b}$ One-factor ANOVA did not reveal a significant change in duration for repetitive units, with $p=0.692, F=0.56$, $\mathbf{d f}=24$.

- One-factor ANOVA indicated a significant change in phase 2 duration, with $p=0.0001, F=9.94, \mathrm{df}=70$. Stage 22 differed from stage 24 at the $95 \%$ level, and stages 20 and 21 differed from stages 23 and 24 at the $99 \%$ level.

${ }^{d}$ One-factor ANOVA did not reveal a significant change in phase 2 duration for repetitive units, with $p=0.774, F=0.45$, df $=24$.

' One-factor ANOVA did not reveal a significant change in amplitude for tonic units, with $p=0.692, F=0.56, \mathrm{df}=24$. 


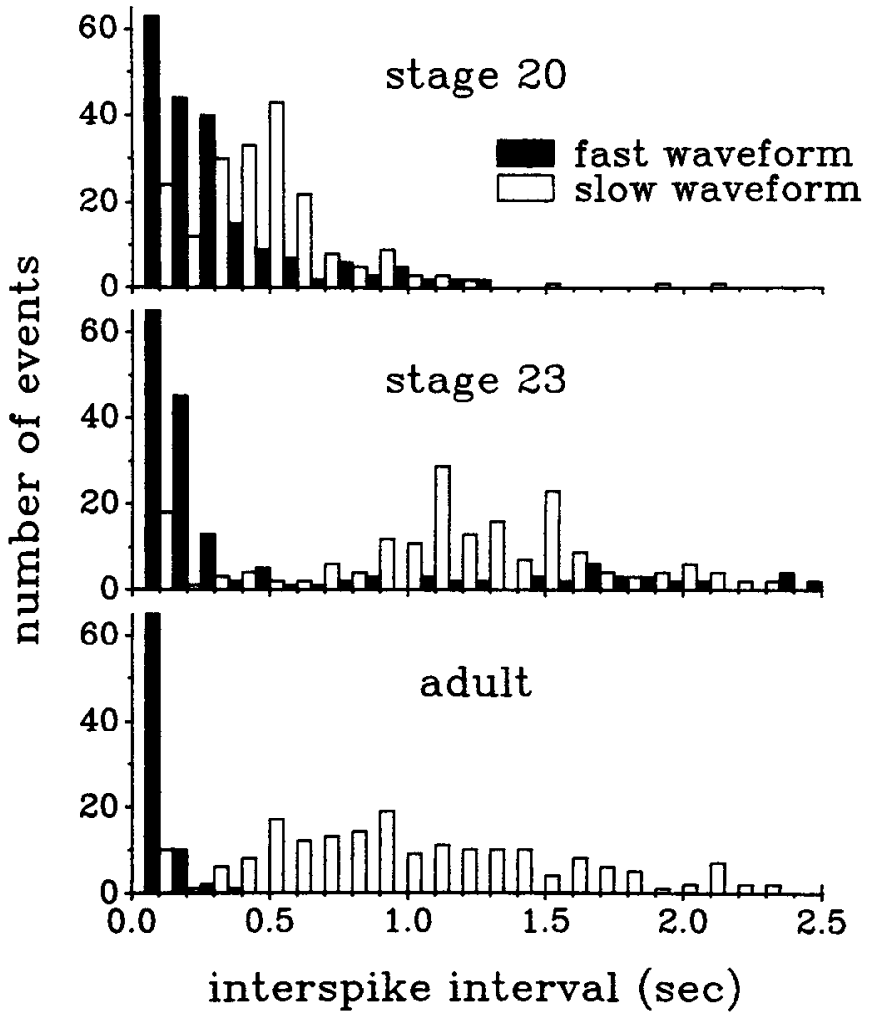

Figure 5. Interspike interval histograms indicate that the difference in firing patterns for slow and fast waveform units becomes accentuated with development. Recordings in which both fast and slow waveform units are present allow comparison of firing patterns of cells in close proximity. In such dual recordings, the cell with the faster waveform fired steadily at a slow rate and also in bursts of higher frequencies that increased in rate with development. The slow waveform units fired tonically at approximately $1 \mathrm{~Hz}$.

reversed from an inward current at potentials hyperpolarized below $-70 \mathrm{mV}$ to an outward current at depolarized potentials (Fig. 7). These currents correspond to inhibitory postsynaptic currents (IPSCs) and, because they reverse near the calculated

\begin{tabular}{|c|c|c|c|c|c|c|}
\hline \multirow[b]{2}{*}{ Stages } & \multicolumn{3}{|l|}{ EPSCs } & \multicolumn{3}{|l|}{ IPSCs } \\
\hline & $\begin{array}{l}\text { Ob- } \\
\text { served }\end{array}$ & $n$ & $\%$ & $\begin{array}{l}\mathrm{Ob}- \\
\text { served }\end{array}$ & $n$ & $\%$ \\
\hline 17 & 0 & 12 & 0 & 0 & 11 & 0 \\
\hline 18 & 9 & 33 & 27 & $0^{*}$ & 26 & 0 \\
\hline 19 & 4 & 14 & 28 & $1^{*}$ & 13 & 8 \\
\hline 20 & 31 & 33 & 94 & 11 & 19 & 58 \\
\hline 21 & 21 & 21 & 100 & 15 & 16 & 94 \\
\hline $22-23$ & 21 & 21 & 100 & 21 & 21 & 100 \\
\hline $24-25$ & 6 & 6 & 100 & 6 & 6 & 100 \\
\hline 26 & 20 & 20 & 100 & 20 & 20 & 100 \\
\hline Total & & 214 & & & 188 & \\
\hline
\end{tabular}

*, IPSCs were present as single or multiple IPSCs in eight additional cells (four at stage 18 , four at stage 19) in preparations in which thalamocortical or corticortical axons were stimulated.

equilibrium potential for chloride $\left(E_{\mathrm{Cl}}=-74 \mathrm{mV}\right)$, are presumed to be chloride currents. A second synaptic current type, corresponding to excitatory postsynaptic currents (EPSCs), reversed at a more depolarized potential, near $0 \mathrm{mV}$, the calculated equilibrium potential for cations $\left(E_{\text {cat }}\right)$. The distinct reversal potentials of EPSCs and IPSCs allow each population to be studied in isolation, inward EPSCs at $-70 \mathrm{mV}$ and outward IPSCs at $-20 \mathrm{mV}$. At intermediate potentials $(-40$ to $-50 \mathrm{mV})$ both currents are clearly resolved but with differing directions of net current flow, allowing effects of pharmacologic agents on each population to be easily compared.

Spontaneous IPSCs and EPSCs exhibited distinct pharmacology. IPSCs reversed at the $E_{\mathrm{Cl}}$, suggesting that they could be $\mathrm{Cl}^{-}$currents mediated by $\mathrm{GABA}_{\mathrm{A}}$ receptors (see Bormann, 1988). When the competitive $\mathrm{GABA}_{\mathrm{A}}$ receptor antagonist BMI (5-10 $\mu \mathrm{M})$ was added to the bathing solution, IPSCs but not EPSCs were reversibly blocked (Fig. $8 A$ ). BMI blocked spontaneous IPSCs when they first appeared at stages 20 and $21(n=8)$ and in older embryos at stages 25 and $26(n=3)$. Beginning at stage 21 and in all older embryos, BMI application led to periodic

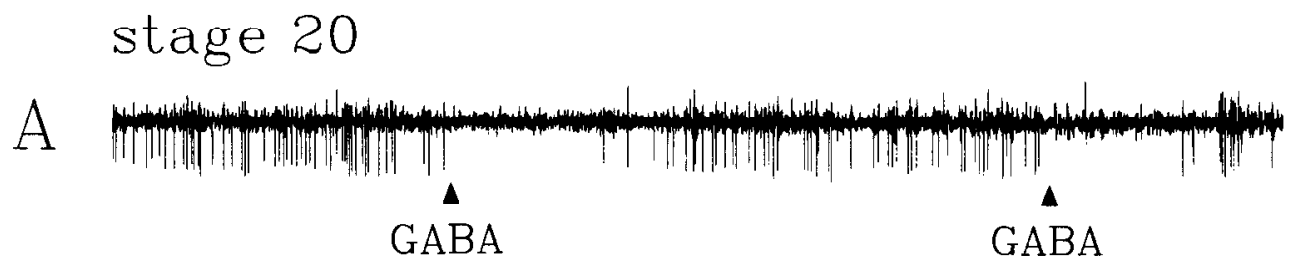

Figure 6. Bursts by fast waveform units, likely nonpyramidal cells, are correlated with inhibition of slow waveform units. At stage 20 , focal GABA application inhibits spontaneous AP activity $(A)$, as does intracortical afferent stimulation (Stim, B). In multiunit recordings, bursts of fast waveform unit activity are correlated with transient inhibition of simultaneously recorded slow waveform units (C). The fast waveform units thus likely correspond to nonpyramidal cells $(N P)$ that are known to inhibit pyramidal cells $(P)$ by release of GABA (Kriegstein and Connors, 1986).
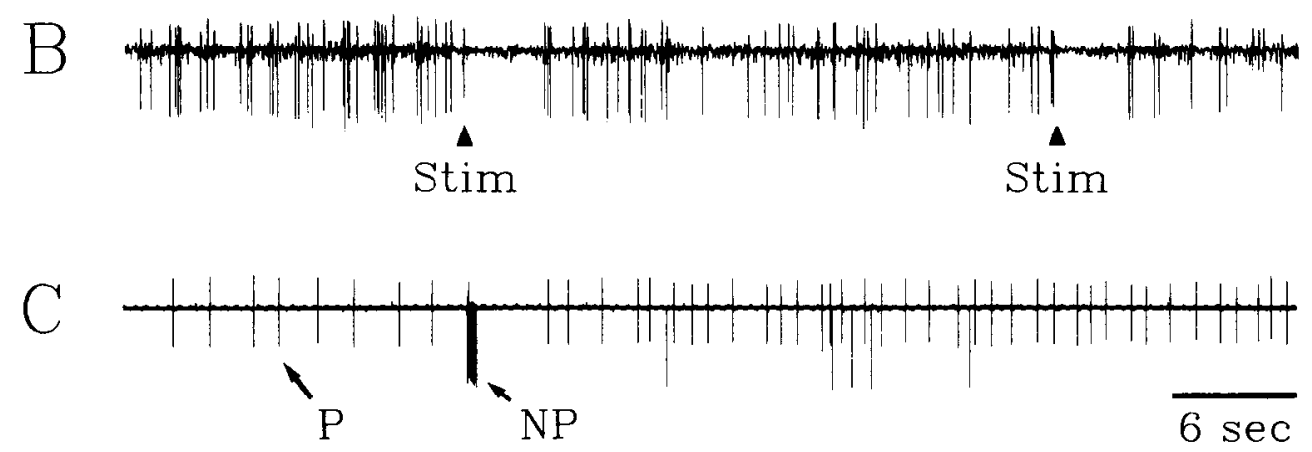


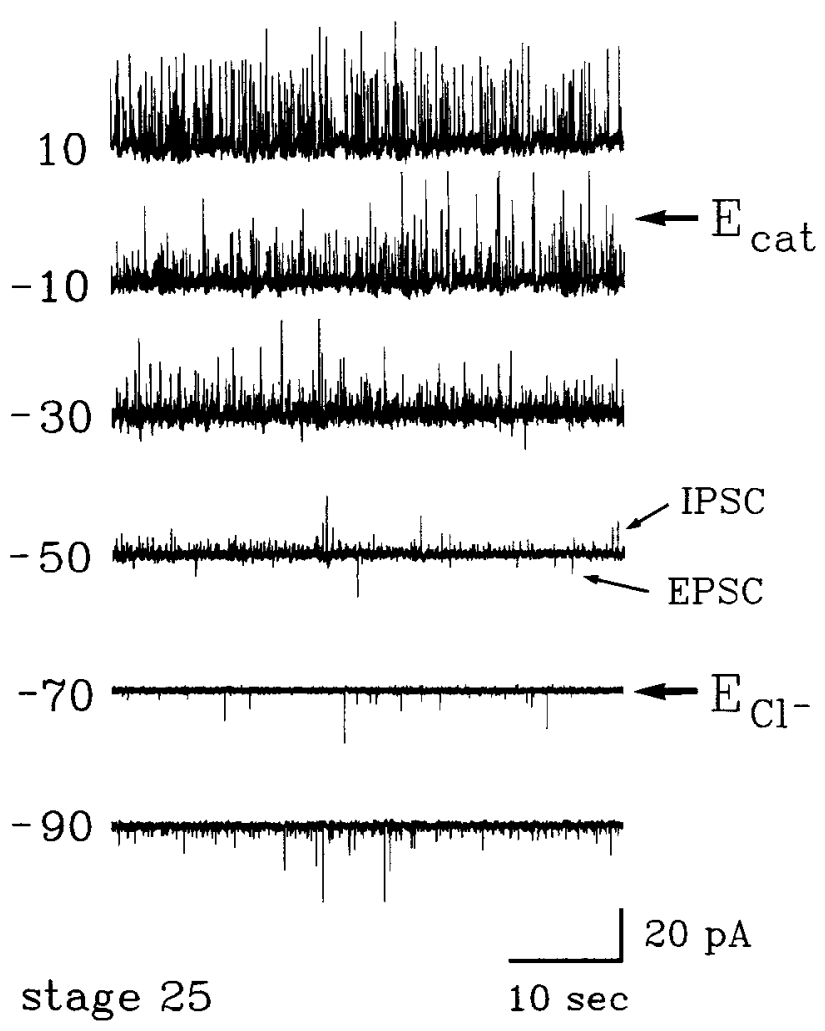

Figure 7. Spontaneous excitatory and inhibitory synaptic currents can be distinguished by their reversal potentials. At a holding potential of $-50 \mathrm{mV}$, both inward currents, corresponding to EPSCs (downward deflections) and more frequent outward currents, corresponding to IPSCs (upward deflections) are observed in a relatively mature stage 25 embryo. The IPSCs reverse in polarity at $-70 \mathrm{mV}$, near the equilibrium potential for chloride $\left(E_{\mathrm{C})}\right)$ and arc inward at $-90 \mathrm{mV}$. The EPSCs reverse in polarity near $0 \mathrm{mV}$, the equilibrium potential for cations $\left(E_{\text {cat }}\right)$. Only outward events are observed at $+10 \mathrm{mV}$.

spontaneous excitatory synaptic currents that correspond to previously observed interictal epileptiform discharges (Fig. 8A; see also Shen and Kriegstein, 1989).

Fast, spontaneous cortical EPSCs that reverse near the $E_{\text {cat }}$ have been found to be sensitive to CNQX (LoTurco et al., 1990), a non-NMDA receptor antagonist (Honoré, 1989). When CNQX (4-10 $\mu \mathrm{M})$ was added to the bathing solution, EPSCs in embryonic turtle neurons were reversibly blocked (Fig. $8 B$ ); no obvious effect on IPSCs was noted, as previously observed in hippocampus (Otis et al., 1991). CNQX blocked EPSCs at the carlicst stage tested, stage $20(n=4)$, and at later stages (stages 25-26; $n=2$ ).

\section{Developmental appearance of spontaneous EPSC's}

Spontaneous EPSCs were first observed at stage 18 and were found in 9 of 33 cells, or $27 \%$. By stage 20, nearly all neurons tested ( 31 of 33 , or $94 \%$ ) exhibited EPSC activity (Table 2). When they first appcarcd, spontancous EPSCs wcre clcarly rcsolvable above baseline noise and showed characteristic rapid rise and exponential decay (Fig. 9A,B). No transient currents that appeared to be precursor forms of synaptic currents were observed at earlier stages. The mean peak current amplitudes when measured on averaged traces corresponded to mean values indicated by amplitude distribution histograms (Fig. 9C).

The mean amplitudes of spontaneous EPSCs, when they first appeared at stage $18(8.1 \pm 2.1 \mathrm{pA}$ at $-70 \mathrm{mV})$, resembled those in more mature neurons at stage $26(8.8 \pm 1.4 \mathrm{pA}$ at -70 $\mathrm{mV}$; Fig. $10 A, B$; see Table 3 for statistical analysis and further detail). A mean current amplitude of $8.8 \pm 1.4 \mathrm{pA}$ at $-70 \mathrm{mV}$ corresponds to a mean EPSC conductance of $126 \pm 20 \mathrm{pS}$. The EPSC amplitudes in three identified nonpyramidal cells were significantly larger (mean amplitude of $16.4 \pm 1.4 \mathrm{pA}$ ) than those in pyramidal cells at the same stage (Table 3 ). In contrast to the developmental stability of EPSC amplitudes, EPSC frequency showed a significant change during development, appearing at stage 18 and increasing progressively from $0.2 \pm 0.1$ $\mathrm{Hz}$ at stage 20 to $3.2 \pm 2.0 \mathrm{~Hz}$ at stage 26 (Fig. 10A,C; Table 3).

The EPSC waveforms also changed during development. The rise times to peak current and the time constants of decay $(\tau)$ showed significant changes, both increasing (Fig. $11 \mathrm{~A}, \mathrm{C}, \mathrm{D}$; Table 3 ). One possible contributor to this change in waveform is the dendritic elongation and increased electrotonic distance that

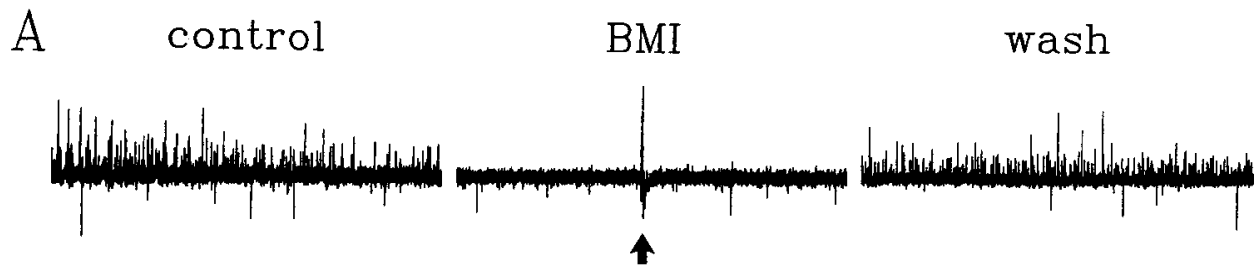

$\mathrm{B}$ control CNQX

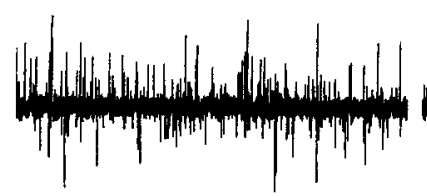

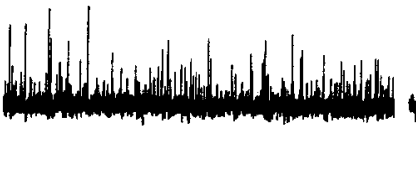

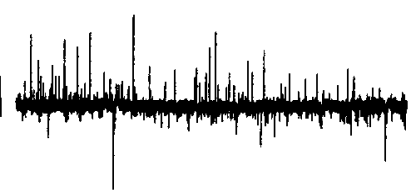

stage 25

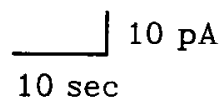

Figure 8. Excitatory and inhibitory synaptic currents are differentially sensitive to amino acid receptor antagonists. With the membrane potential held at $-40 \mathrm{mV}$, outward IPSCs (upgoing events) but not inward EPSCs (downgoing) are blocked reversibly by the $\mathrm{GABA}_{\mathrm{A}}$ receptor antagonist BMI in a stage 25 neuron. Periodic synaptic cvents corresponding to epileptiform discharges are observed in BMI (arrow; see also Shen and Kriegstein, 1989) and consist of EPSCs and slow outward currents. $B$, Spontaneous EPSCs, but not IPSCs, are reversibly blocked by the non-NMDA glutamate receptor antagonist CNQX. 

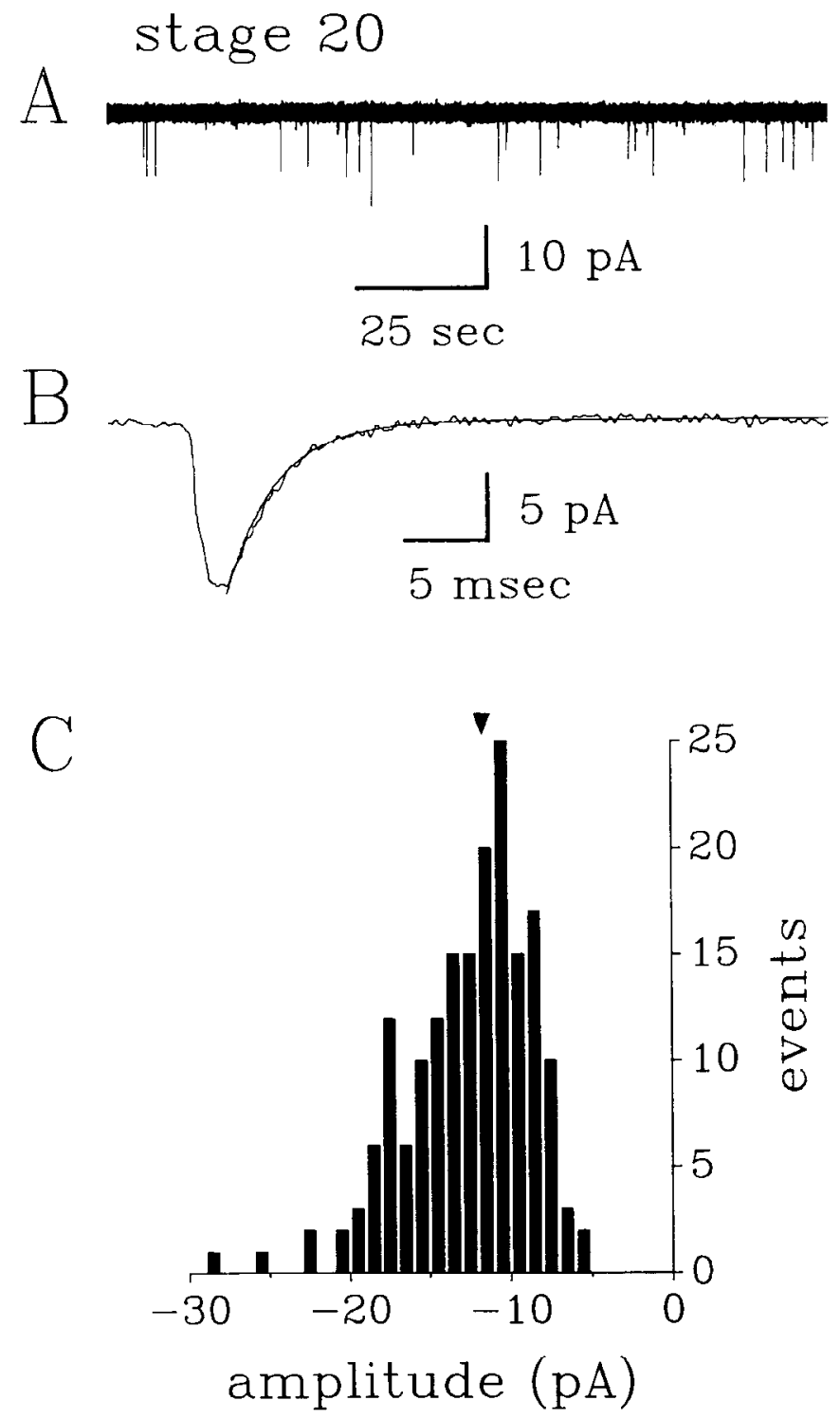

Figure 9. Spontaneous excitatory synaptic currents are easily resolved in embryonic cortical neurons. $A$, With the cell held at the reversal potential for IPSCs $(-70 \mathrm{mV})$, spontaneous inward EPSCs are observed in a stage 20 neuron. $B$, The EPSCs rise rapidly to peak and then decay exponentially. The trace, an average of 30 EPSCs from the cell in $A$, was fitted by a single exponential with a time constant of 3.1 msec. $C$, Amplitude histogram of synaptic currents in this cell. The mean amplitude, measured from the averaged trace, was $-11.8 \mathrm{pA}$ at $-70 \mathrm{mV}$ and is marked on the amplitude distribution with an arrowhead.

occurs during the same period, observed by biocytin injections that revealed cell morphology (Fig. 11B).

In summary, spontaneous EPSCs appear at stage 18 and increase progressively in frequency, rise time, and $\tau$ during embryonic life. The EPSC amplitudes, however, are similar throughout development, despite dendritic elongation.

\section{Developmental appearance of IPSCS}

IPSCs appeared over a time course that differed from that of EPSCs. While spontaneous EPSCs were commonly observed at stages 18 and 19 , spontaneous IPSCs were observed only in a single cell (see Table 2, Fig. 12). IPSCs were, however, observed in preparations at stages 18 and 19 in which afferent or intracortical axons were stimulated repetitively ( $n=8$; Fig. 12A). Spontaneous IPSCs appeared suddenly in late stage 20 and 21 embryos, and soon surpassed the earlier appearing EPSCs in frequency (Fig. 12A,C; Tables 3, 4). In parallel with the increased frequency, and in contrast to EPSCs, the IPSC's showed a significant change in mean amplitude with development (Fig. $12 A, B$; Table 4), increasing from $9.0 \pm 0.6 \mathrm{pA}$ at stage 18 to $13.0 \pm$ 2.2 at stage 26 . This increase in current amplitude, measured at a holding potential of $-20 \mathrm{mV}$, corresponds to an increase in mean conductance from $180 \pm 12 \mathrm{pS}$ to $260 \pm 44 \mathrm{pS}$. During the time of transition, IPSC amplitudes showed substantial variation from cell to cell (see stage 20, Fig. 12B). The increase in amplitude was dependent on sodium AP activity, as bathing the cortex in TTX $(1 \mu \mathrm{M})$ returned the amplitudes to smaller values (Fig. 12B; see also below).

The waveform parameters of IPSCs also changed in development. The rise times of IPSCs, like those of EPSCs, showed a significant developmental change (Fig. 13B, Table 4), increasing from $2.9 \pm 0.18 \mathrm{msec}$ at stage $18(n=2)$ to $6.2 \pm 0.83$ msec at stages $25-26(n=4)$. Decay time constants did not show a statistically significant change, although a decreasing trend was observed (Fig. 13A,C; Table 4).

In summary, spontaneous IPSCs appeared relatively suddenly in development and quickly surpassed EPSCs in frequency. In contrast to EPSCs, IPSCs increased in amplitude and showed no significant change in decay time constant during development.

\section{Relationship of spontaneous synaptic currents to APs}

To test the relationship of spontaneous APs to spontaneous synaptic currents during early synapse formation, TTX was added to the bathing solution during recordings from young stage 20 and 21 neurons. TTX produced a pronounced decrease in both the frequency and mean amplitude of spontaneous IPSCs (Figs. 14, 15; Table 4). In stage $21+$ cells, the frequency of IPSCs decreased from $3.1 \pm 0.7 \mathrm{~Hz}$ in control to $0.3 \pm 0.1 \mathrm{~Hz}$ in TTX, and the mean IPSC amplitudes were decreased from 13.8 $\pm 0.7 \mathrm{pA}$, in control, to $9.5 \pm 1.5 \mathrm{pA}$ in TTX $(n=3$; see Table 4 for details and statistics). The IPSC amplitudes in TTX appear to be a subset of the IPSC amplitudes in control conditions (Figs. 14B, 15). An effect of TTX on EPSCs was also observed at these stages but was less pronounced (Fig. 15). In the presence of TTX, EPSC frequency decreased from $0.5 \pm 0.1 \mathrm{~Hz}$ to 0.1 $\pm 0.1 \mathrm{~Hz}(n=3)$ or showed no change $(n=1)$, but there was no change in EPSC amplitude. Due to the low frequency of EPSCs at early stages, the AP dependence of EPSCs was not explored further.

\section{Discussion}

Spontaneous electrical activity, in the form of APs and synaptic currents, begins early in the development of the embryonic cerebral cortex, following the expression of amino acid neurotransmitters (Blanton and Kriegstein, 1991b) and their receptors (Blanton et al., 1990; Blanton and Kriegstein, unpublished observations). This spontaneous neuronal activity emerges in a characteristic sequence (summarized in Fig. 16) and provides the required substrate for the involvement of electrical activity in shaping development in vivo (see Harris, 1981; Mattson, 1988; see also below). 
A stage 18

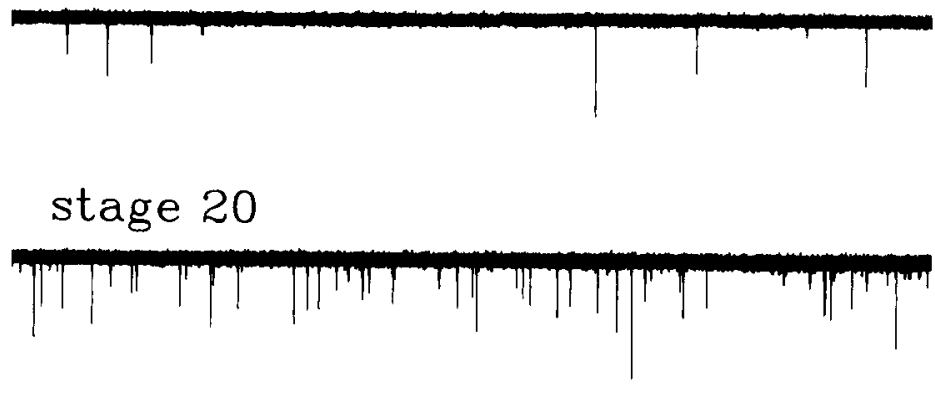

stage 23

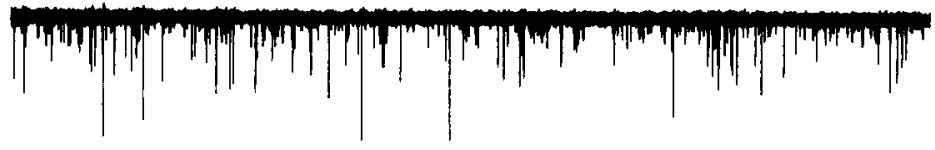

stage 25

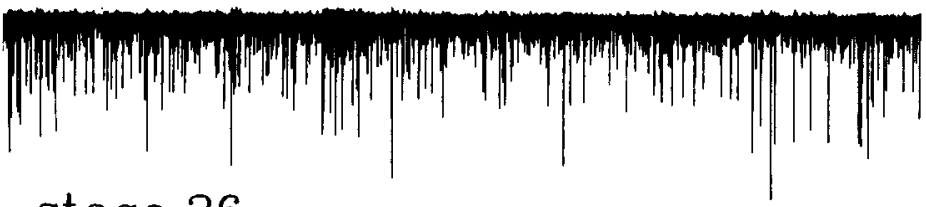

stage 26

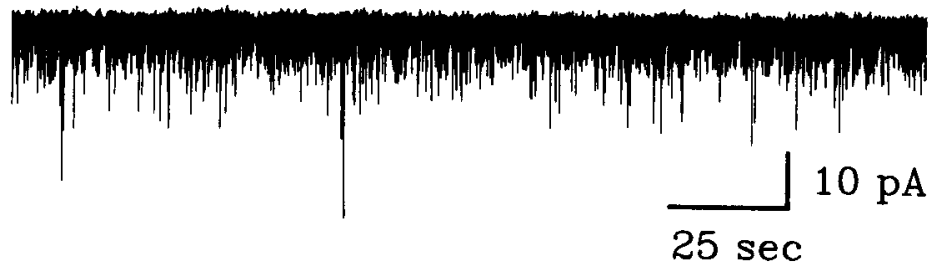

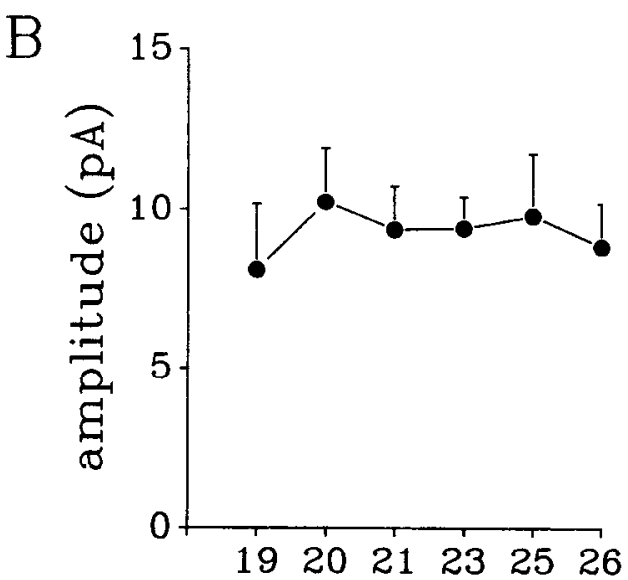

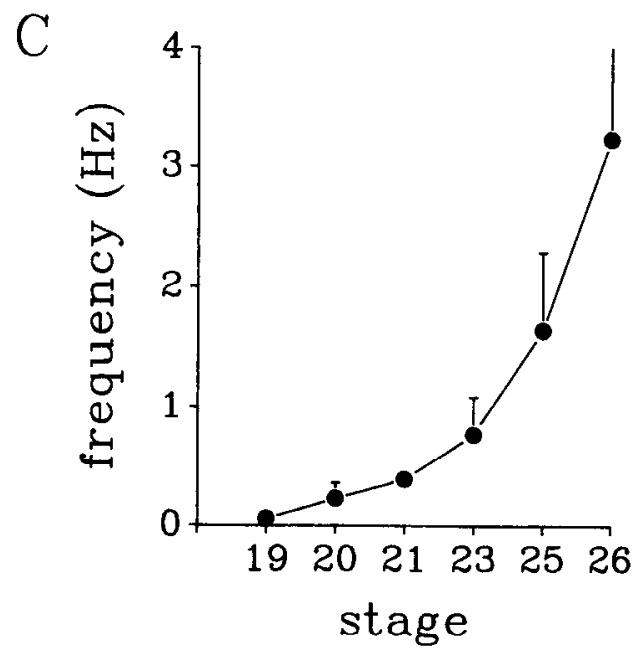

Figure 10. Spontaneous EPSCs increase in frequency but not amplitude during embryonic development. $A$, When spontaneous EPSCs appear at stage 18, they resemble currents observed at later stages in amplitude but are less frequent. $B$, The mean amplitudes of EPSCs do not change significantly during development (error bars correspond to SD). Stage 19 values are derived from pooled stage 18 and 19 data. $C$, Spontaneous EPSCs increase in frequency gradually but progressively during embryonic life. See Table 3 for further detail and statistical analysis.

Table 3. Spontaneous excitatory synaptic currents $\left(\mathrm{V}_{\text {hold }}=-70 \mathrm{mV}\right)$

\begin{tabular}{lccll} 
Stage & Amplitude $(\mathrm{pA})^{a}$ & \multicolumn{2}{c}{ Frequency $(\mathrm{Hz})^{b}$} & \multicolumn{2}{l}{ Rise time (msec) $^{c}$} & $\tau$-Decay $(\mathrm{msec})^{d}$ \\
\hline $18-19$ & $-8.1 \pm 2.1(5)$ & $<0.06 \quad(5)$ & $1.8 \pm 0.3(5)$ & $4.2 \pm 0.4(4)$ \\
20 & $-10.2 \pm 1.7(10)$ & $0.2 \pm 0.1(9)$ & $1.5 \pm 0.5(10)$ & $3.9 \pm 1.2(10)$ \\
21 & $-8.8+2.3(5)^{*}$ & $0.4 \pm 0.1(5)^{*}$ & $2.1 \pm 0.5(5)^{*}$ & $6.2 \pm 2.3(5)^{*}$ \\
$22-23$ & $-9.4 \pm 1.1(5)$ & $0.8 \pm 0.4(5)$ & $2.6 \pm 1.1(5)$ & $6.3 \pm 1.9(5)$ \\
$24-25$ & $-9.8 \pm 2.0(4)$ & $1.6 \pm 0.7(5)$ & $3.1 \pm 0.5(5)$ & $8.4 \pm 1.7(5)$ \\
26 & $-8.8 \pm 1.4(16)$ & $3.2 \pm 2.0(12)$ & $2.7 \pm 0.6(15)$ & $8.7 \pm 2.3(13)$ \\
21 (nonpyramidal) & $-16.3 \pm 1.4(3)^{*}$ & $0.9 \pm 0.6(3)^{*}$ & $2.1 \pm 1.2(3)^{*}$ & $7.4 \pm 5.8(3)^{*}$
\end{tabular}

Values shown are mean \pm PSD $(n)$.

*, Two-tailed unpaired $t$ test indicated that at stage 21, EPSC amplitudes in pyramidal and nonpyramidal cells were significantly different, with $p=0.0005$; no statistically significant differences were noted in other parameters.

a One-factor ANOVA did not reveal a significant change in amplitude during embryonic development, with $p=0.15$, $F=1.73, \mathrm{df}=44$.

${ }^{b}$ One-factor ANOVA indicated a significant change in frequency, with $p=0.0001, F=7.93, \mathrm{df}=35$. A post hoc Scheffé $F$ test indicated that stages $20-22$ differed from stage 26 at the $95 \%$ confidence level and stages 20 and 26 differed at the $99 \%$ level.

' One-factor ANOVA indicated a significant change in rise time, with $p=0.0001, F=7.28$, df $=44$. Stage 20 differed from stages 24 and 26 at the $99 \%$ level.

${ }^{d}$ One-factor ANOVA indicated a significant change in $\tau$, with $p=0.0001, F=9.27, \mathrm{df}=41$. Stages 18 and 20 differed from stages 24 and 26 at the $95 \%$ level, and stage 20 differed from 26 at the $99 \%$ level. 
A

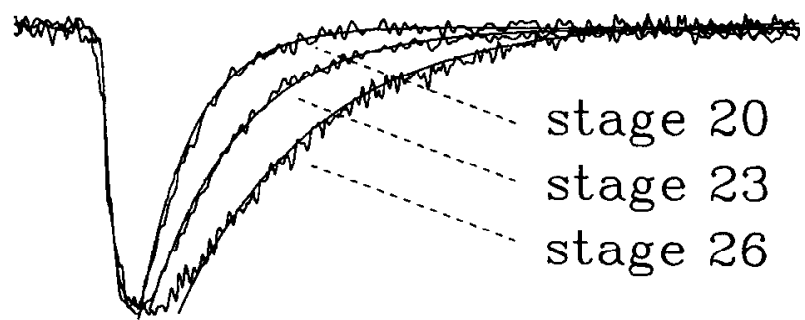

$5 \mathrm{pA}$

$10 \mathrm{msec}$

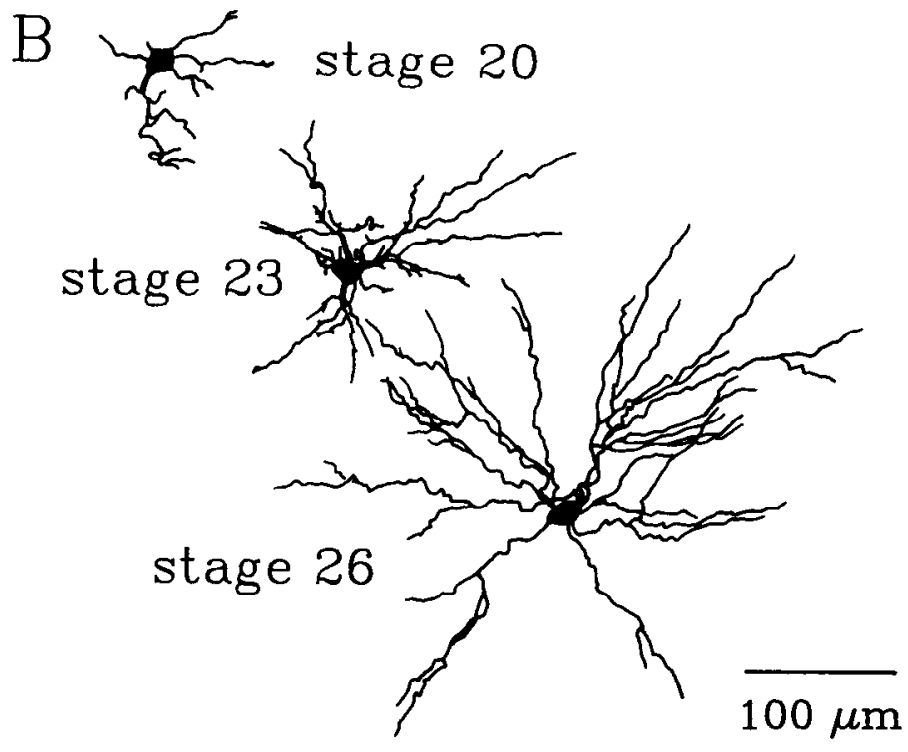

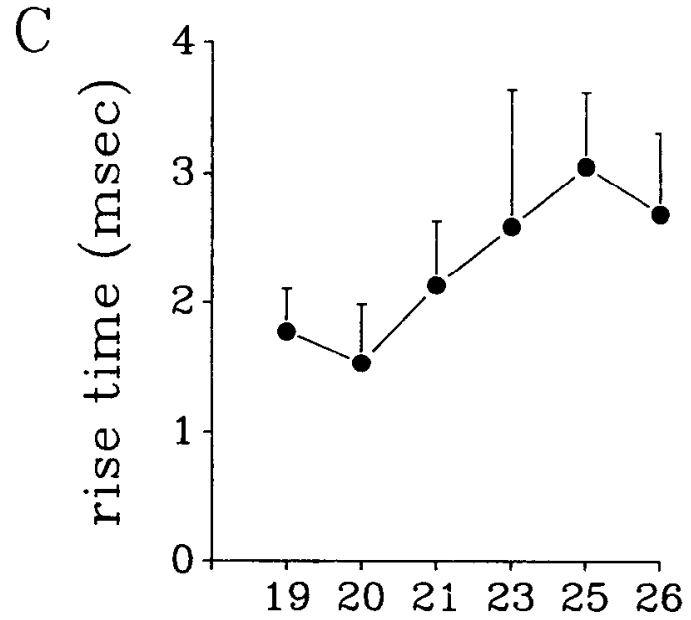

$\mathrm{D}$

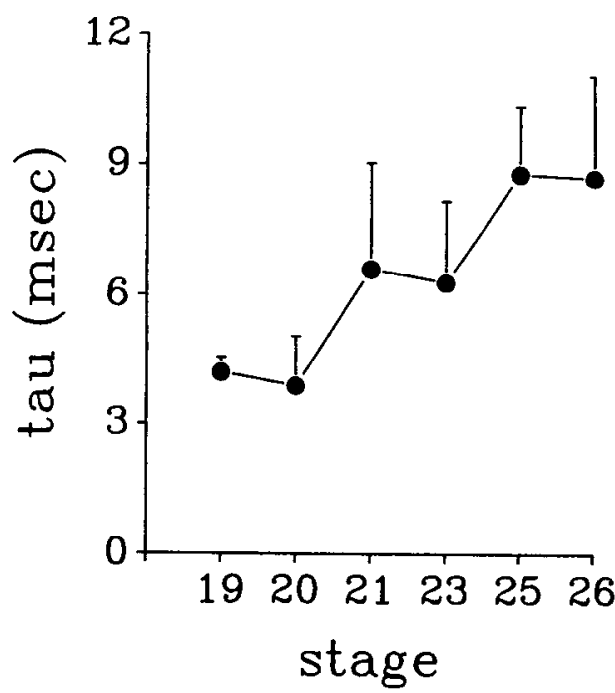

Figure 11. EPSC waveforms change during development. A, Averaged traces reveal a clear showing of synaptic current decay with development. The single exponential decays superimposed on each trace correspond to time constants of 3.1 msec for the stage 20 trace, 5.0 msec for stage 23 , and $8.3 \mathrm{mscc}$ for stage 26. $B$, Camcra lucida drawings of biocytin-labeled pyramidal cells at these stages (horizontal plane) illustrate dendrite elongation during embryonic life; the increasing electrotonic distances would be expected to influence synaptic current waveform. $C$, Rise times to peak, as well as time constants of decay $(t a u, D)$ both increased in development. Error bars correspond to SD; see Table 3 for details and statistical analysis.

\section{Spontaneous AP activity}

Sporadic AP activity appeared early in development, resembling the spontaneous AP activity encountered in early postnatal mammalian cortex (Huttenlocher, 1967; Armstrong-James, 1975). Activity appeared soon after morphologically identifiable pyramidal and nonpyramidal cells are observed in the cortex (Blanton and Kriegstein, 1991a). With development, spontaneous activity became more regular, and APs became briefer (see Schwartzkroin, 1982; McCormick and Prince, 1987; Prince and Huguenard, 1988). By stage 20, two different spontaneous firing patterns had emerged, relatively slow, tonic firing units, and faster, intermittent, repetitive firing units, likely reflecting the activity of pyramidal and nonpyramidal cells. These distinct properties of pyramidal and nonpyramidal neurons have previously been noted in mature cortex and have been observed in both intracellular (McCormick et al., 1985; Connors and
Kriegstein, 1986; Prince and Huguenard, 1988; Connors and Gutnick, 1990) and extracellular (Mountcastle et al., 1969) studies.

In contrast to results in cortical cell culture in which spontaneous AP activity emerged and developed in parallel with excitatory synaptic circuits and in which each AP appeared to be driven by a synaptic event (Jackson et al., 1982; Westbrook and Brenneman, 1984), we found that in intact embryonic cortex, spontaneous AP firing preceded discrete excitatory synaptic events in development. In addition, during early circuit formation, APs occurred at higher frequency than synaptic events $(0.43-0.63 \mathrm{~Hz}$ for APs at stages $17-19$, and $0.06 \mathrm{~Hz}$ for EPSCs at stages 18-19) and therefore could not have been driven by EPSCs exclusively. This appearance of AP discharge prior to discrete synaptic activity could reflect the activity of nonsynaptic depolarizing influences on neurons, for example, the tonic background current mediated through NMDA receptors (Blan- 
A

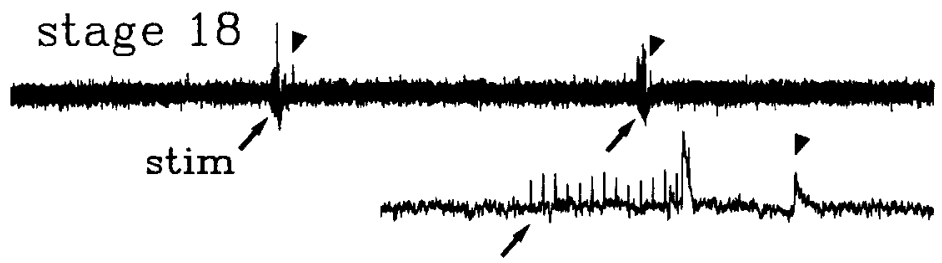

spontaneous
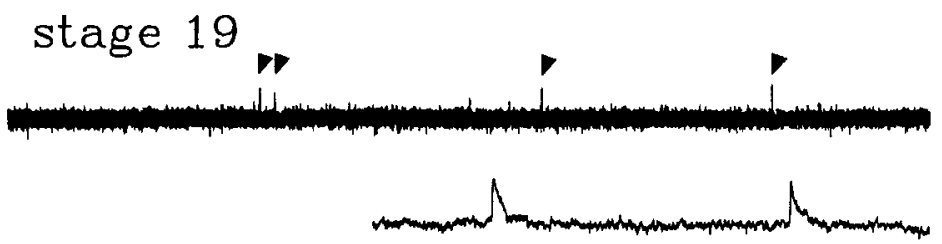

stage 21
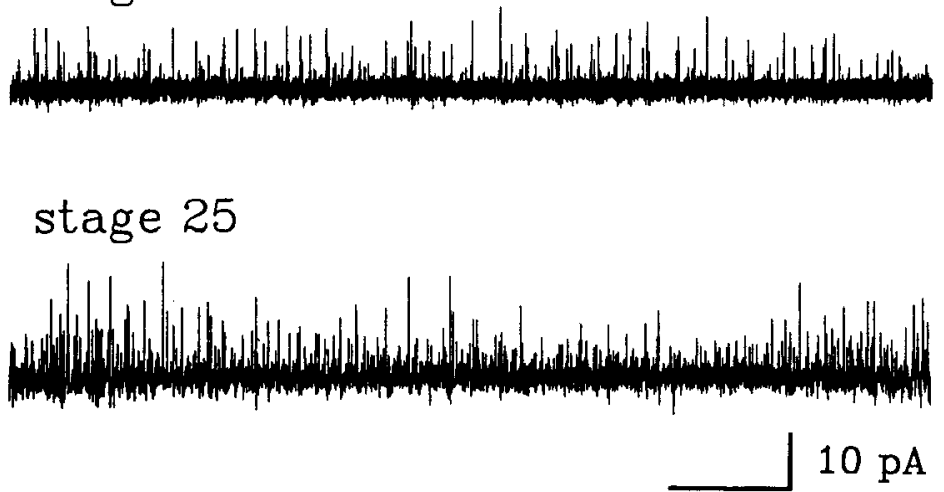

$10 \mathrm{sec}$

$500 \mathrm{msec}$

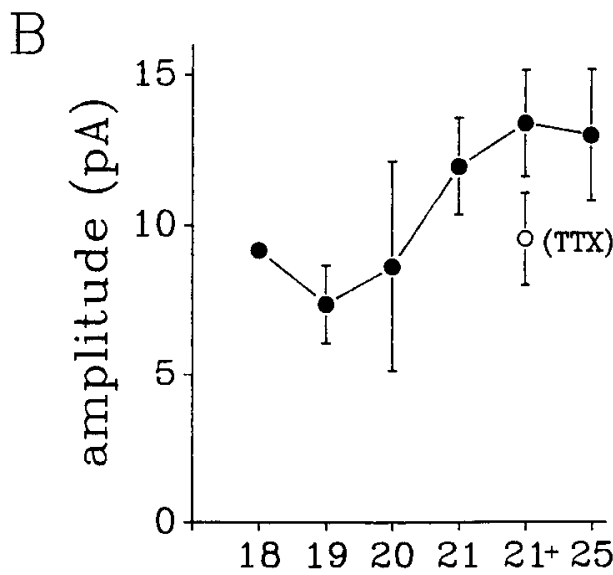

C

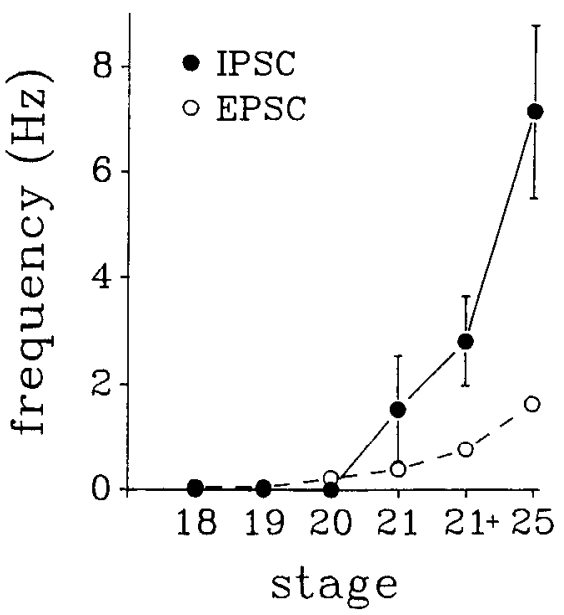

Figure 12. Spontaneous IPSCs increase in amplitude and frequency during development. $A$, At stage 18 IPSCs (arrowheads, upward deflections at $-20 \mathrm{mV}$ ) were observed only after repetitive stimulation of thalamocortical axons (arrows, $20 \mathrm{~Hz}$ for $700 \mathrm{msec}$ ). The inset shows the response with an expanded time base, and the arrowhead indicates an evoked IPSC. Infrequent spontaneous IPSCs were observed in rare cells at stages 19 and 20. The expanded trace (inset) shows a pair of spontaneous IPSCs from the initial portion of the stage 19 trace. IPSCs increased in frequency suddenly at stage 21 and continued to increase during embryonic life. Scale bar for $10 \mathrm{sec}$ corresponds to all traces except the expanded insets, in which the bar corresponds to $500 \mathrm{msec}$. The amplitudes of events in the unexpanded traces are slightly attenuated due to AC coupling used for plotting. $B$, Amplitudes of synaptic currents increase during embryonic life. Blockade of APs decreased the mean current in neurons at stage $21+$ to levels resembling that of younger stages. $C$, IPSCs increased in frequency suddenly at stage 21 , in contrast to EPSCs that increased during development in a gradual way (see Fig. 10). See Table 4 for details and statistical analysis.

ton et al., 1990; LoTurco et al., 1991). NMDA receptor activation has been shown to increasc cxcitability, cnhancing spontaneous (Armstrong-James et al., 1985) or evoked (Sah et al., 1989) AP discharge. The differing dependence of spontaneous APs on synaptic input in culture and slices could, alternatively, reflect the ratios of inward and outward voltage-activated conductances in the distinct cell types (Prince and Huguenard, 1988) or the effect of neuromodulators, each of which may be altered in the culture environment. Additionally, the timing of expression of voltage-gated channels in relation to synaptic differentiation and expression of ligand-gated channels may differ in vitro and in vivo.

In other systems, AP activity has been shown to affect neurite outgrowth (Cohan and Kater, 1986), neuronal survival (Bergey et al., 1981), and through its modulation of neurotransmitter release, neural topographic representations (Chapman et al., 1986; Dubin et al., 1986; Shatz and Stryker, 1988; Nelson et al., 1989; Shatz, 1990). The AP activity observed in developing turtlc cercbral cortcx is likcly to play an important developmental role. While not required for the formation of synapses in turtle cortex (Wilson et al., 1988), AP-dependent activity is required for the development of normal excitability (Desan, personal communication). Whether the role of action potential activity in the developmental control of excitability is permissive, being required for normal development but not shaping its fine details, or, in contrast, instructive, directing local synapse formation (see Stryker, 1989), remains to be determined.

\section{Appearance of spontaneous synaptic currents}

The recent development of techniques for whole-cell recording in slices has allowed a detailed analysis of differentiation events in relatively intact neural structures with a resolution in young cells previously obtainable only in cells developing in culture (see Jackson et al., 1982). Whole-cell recording in voltage-clamp 
A

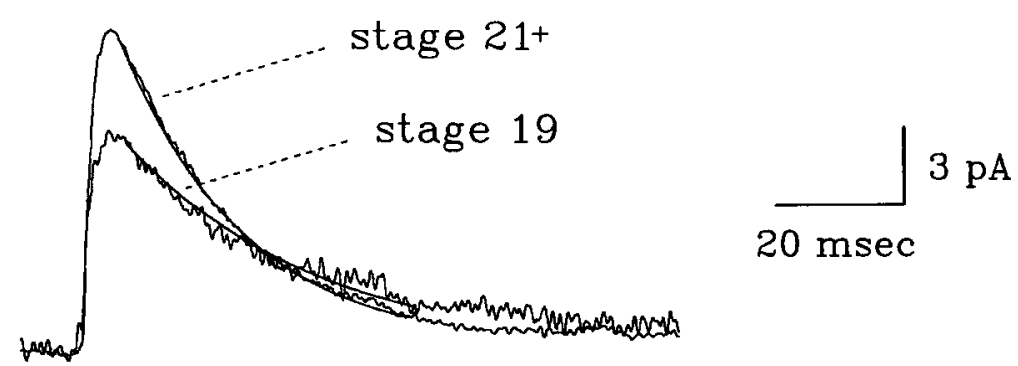

Figure 13. Inhibitory synaptic current waveforms change during development. $A$, IPSCs at stage $21+$ (average of 30 traces) and stage 19 (average of 3 traces) decay exponentially. Note that the time axis differs from that used in previous figures illustrating the faster EPSCs. $B$, The rise time to peak of IPSCs increased in development. $C$, IPSCs show a trend of decreasing decay time constants (tau) that was not statistically significant. Compare with EPSC $\tau$-values in Figure 11, and see Table 4 for details and statistical analysis.
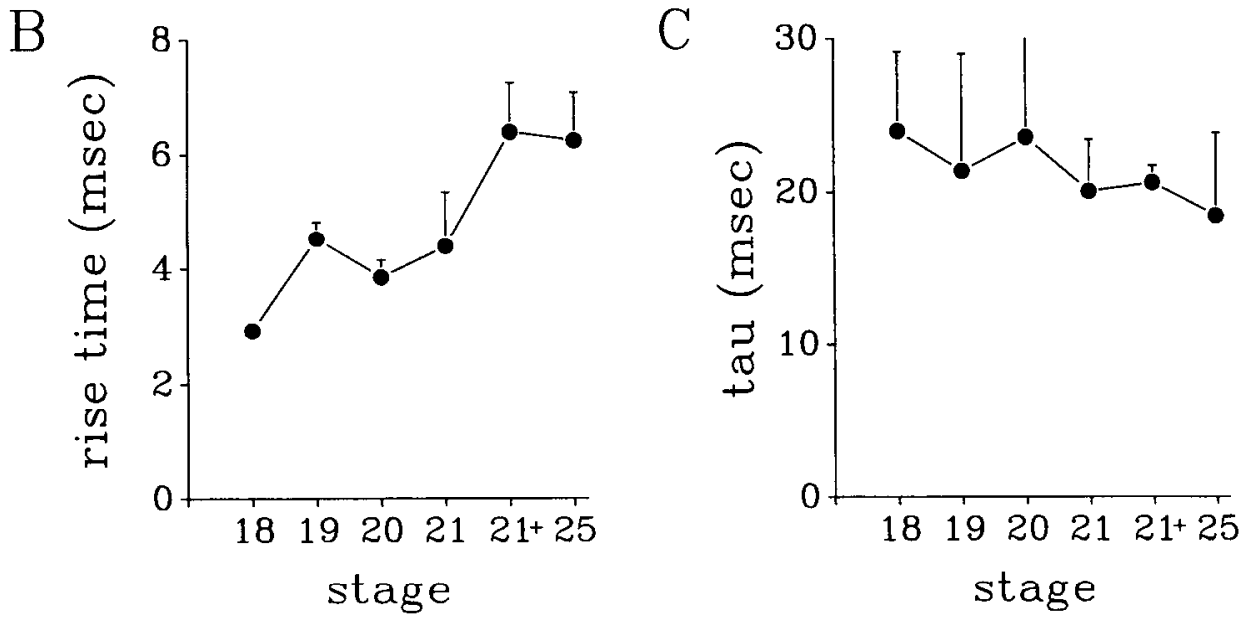

provides major advantages for the study of synaptic differentiation in situ (Blanton et al., 1989) as well as for study of mature synaptic circuits (Edwards et al., 1990; Sah et al., 1990), including superior recording stability and increased sensitivity and temporal resolution compared with microelectrode, currentclamp recording (see Smith et al., 1985). Interpretation of voltage-clamp experiments requires caution, however, especially in branched neurons in intact tissue, due to the problems of electrotonic attenuation and filtering of currents and of maintaining space clamp in distal dendrites (see Brown and Johnston, 1983; Johnston and Brown, 1983; Rall and Segev, 1985; Hestrin et al., 1990).

Spontaneous EPSCs and IPSCs observed in whole-cell recordings showed distinct patterns of emergence during development. Spontaneous EPSCs appeared first, followed by IPSCs, a pattern like that observed for evoked synaptic events in mammalian hippocampus (Schwartzkroin, 1982; Michelson and Lothman, 1989; Schwartzkroin et al., 1989; Swann et al., 1989)

Table 4. Spontaneous inhibitory synaptic currents $\left(\mathbf{V}_{\text {hold }}=-\mathbf{2 0} \mathbf{~ m V}\right)$
\begin{tabular}{lcccll} 
Stage & Amplitude (pA) & \multicolumn{2}{l}{ Frequency $(\mathrm{Hz})^{h}$} & Risc timc (mscc) & $r$-Decay (msec) \\
\hline 18 & $9.0 \pm 0.6(2)$ & $<0.01$ & $(2)$ & $2.9 \pm 0.2(2)$ & $24.0 \pm 5.2(2)$ \\
19 & $6.9 \pm 1.4(4)$ & $<0.01$ & $(4)$ & $4.5 \pm 0.3(3)$ & $21.4 \pm 7.6(3)$ \\
20 & $8.6 \pm 3.5(3)$ & $<0.01$ & $(3)$ & $3.9 \pm 0.3(3)$ & $23.5 \pm 13(3)$ \\
21 & $12.0 \pm 1.6(6)$ & $1.5+1.0(5)$ & $4.4+0.9(6)$ & $20.0 \pm 3.4(5)$ \\
$21+$ & $13.4 \pm 1.8(5)^{*}$ & $2.8 \pm 0.8(5)^{*}$ & $6.4 \pm 0.9(5)^{*}$ & $20.6 \pm 1.1(5)^{*}$ \\
$25-26$ & $13.0 \pm 2.2(4)$ & $7.1 \pm 1.6(3)$ & $6.2 \pm 0.8(4)$ & $18.4 \pm 5.3(4)$ \\
$21+($ in TTX) & $9.5 \pm 1.5(3)^{*}$ & $0.3 \pm 0.1(3)^{*}$ & $5.9 \pm 1.1(3)^{*}$ & $22.9 \pm 1.9(3)^{*}$
\end{tabular}

Values shown are mean $\pm \operatorname{PSD}(n)$.

*, Two-tailed unpaired $t$ test indicated that at stage $21+$, IPSCs observed in the presence versus absence of TTX differed in amplitude $(p=0.021)$ and in frequency $(p=0.0024)$ but not in rise time or $\tau$.

a One-factor ANOVA indicated a significant change in amplitude during embryonic development, with $p=0.0008$ $F=7.13$, df $=23$. A post hoc Scheffé $F$ test indicated that stage 19 was different from stages 21 and 25 at the $95 \%$ confidence level and from stage $21+$ at the $99 \%$ level.

${ }^{b}$ One-factor ANOVA indicated a significant change in frequency, with $p=0.0001, F=28.9, \mathrm{df}=22$. Stages 19 and 20 differed from stage $21+$ at the $95 \%$ level, and stages 18-21 + differed from stage 25 at the $99 \%$ level.

c One-factor ANOVA indicated a significant change in rise time, with $p=0.0001, F=10.63, \mathrm{df}=22$. Stages 20 and 21 differed from $21+$, and 20 from 25 at the $95 \%$ level, and stage 18 differed from $21+$ and 25 at the $99 \%$ level.

${ }^{d}$ One-factor ANOVA did not reveal a significant change in $\tau$, with $p=0.86, F=0.37$, df 22 . 
and cerebral cortex (Kriegstein et al., 1987; Prince and Kriegstein, 1989; see also Friauf et al., 1990) and for spontaneous events in neocortex (J. J. LoTurco, personal communication).

Spontaneous EPSCs are the first synaptic currents to appear in embryos. These EPSCs are mediated by non-NMDA receptors, like spontaneous (LoTurco et al., 1990) and evoked fast EPSCs (Hestrin et al., 1990; Konnerth et al., 1990) in mature cortex. The embryonic EPSCs also resembled mature spontaneous EPSCs in turtles (M. G. Blanton, unpublished observations) and in rats in amplitude (125 $\pm 78 \mathrm{pS}$; LoTurco et al., 1990). The observed constancy of current amplitudes recorded at the soma, however, does not necessarily reflect developmental constancy of the conductance change at synapses. Given the tremendous dendritic elongation that occurs in embryonic life, which would be expected to attenuate EPSCs from distal synapses in older embryos, the similarity in somatic currents through time may indicate that the actual conductance changes at synapses increased. While the synaptic currents measured in the soma are stable in development, the changes in potential at the soma due to the currents would be expected to be larger in young animals, due to high input impedances of embryonic cortical cells [ $514 \pm 215 \mathrm{M} \Omega, n=11$ at stage 21 and $314 \pm 189 \mathrm{M} \Omega$, $n=23$ at stage 26 (recorded with potassium-containing electrodes; see Blanton et al., 1989; Blanton, unpublished observations; see also McCormick and Prince, 1987; Prince and Kriegstein, 1989; Schwartzkroin et al., 1989)].

Developmental changes in conductance and other parameters of EPSC waveform may stem from a variety of causes, including an electrotonic attenuation of synaptic currents in older embryos. The rise times to peak current and the time constants of decay $(\tau)$ of EPSCs both increase by a similar proportion (see Rall, 1977; Brown and Johnston, 1983; Johnston and Brown, 1983). A correlation of increasing rise time with increasing $\tau$, and with decreasing amplitude, as development proceeds would indicate possible increasing electrotonic attenuation of synaptic currents during development, assuming the conductance mechanism at each synapse was stable. The amplitudes of EPSCs did not decrease in parallel as expected if the cause of changes in amplitude, rise time, and $\tau$ were purely electrotonic, and this difference may reflect insertion of additional ligand-gated channels at synapses with maturation. Such insertion could allow increased conductance without changing the rise time or $\tau$. While a trend of a parallel increase in rise time and $\tau$ was observed for the overall population, these properties were not directly related within individual cells (Blanton, unpublished observations). In addition to effects of electrotonic attenuation and filtering, the observed developmental changes in synaptic currents could reflect changes in the conductance mechanism at synapses, through changes in gene expression (Sommer et al., 1990), leading to altered receptor desensitization (Trussell and Fischbach, 1989) or channel mean open time (Moss et al., 1989). Interpretation of spontaneous postsynaptic current parameters during development is further complicated by the likelihood that one is not studying the same population of synapses through time: cortical neurons continue to acquire new synaptic input during embryonic development (J. G. Parnavelas, M. Blanton, and $A$. R. Kriegstein, unpublished observations). In addition, the degree to which excitatory synapses from various sources (thalamic, interhemispheric, association, local) contribute to spontaneous synaptic activity is not yet known and may change with development.

Spontaneous IPSC waveform parameters changed during de-
A

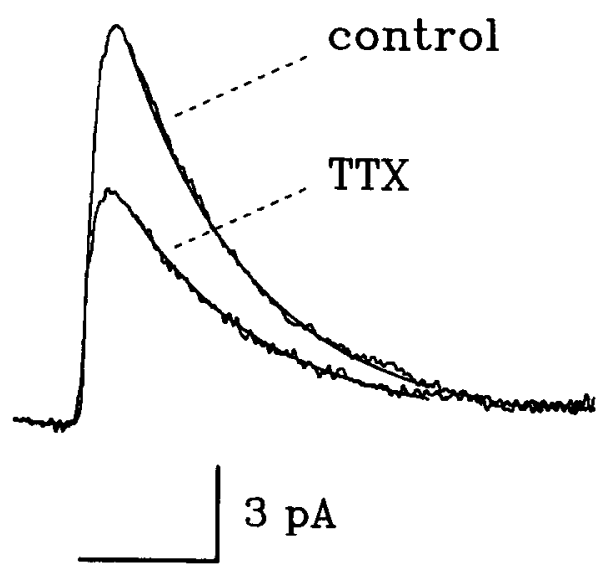

$20 \mathrm{msec}$

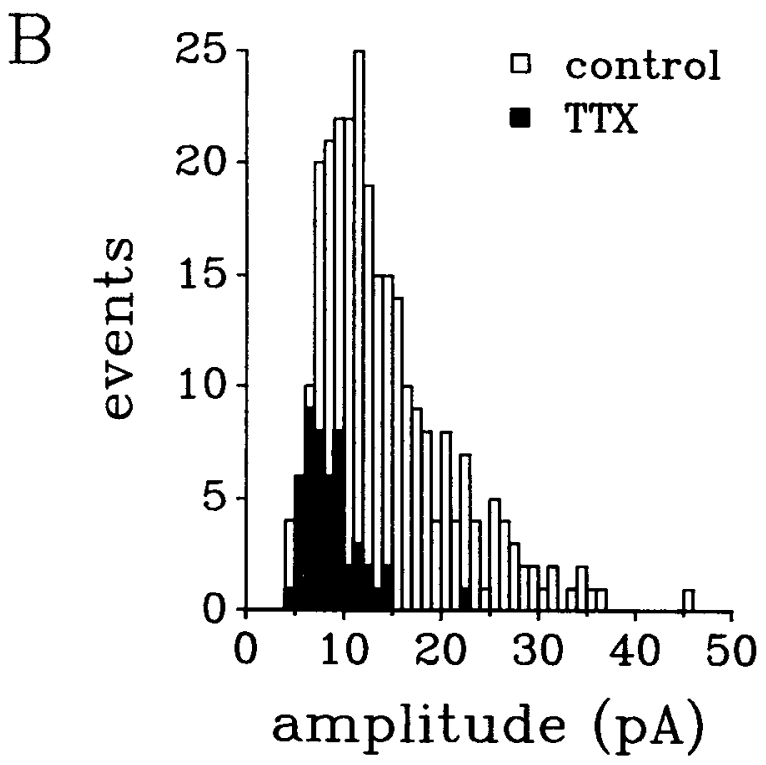

Figure 14. Blockade of sodium AP activity causes a decrease in the mean amplitudes of spontaneous IPSCs at stage 21. $A$, Averaged IPSC traces before and after bathing in TTX show a decrease in amplitude from 12.1 to $7.0 \mathrm{pA}$ but no change in $\tau$ (control, $19.0 \mathrm{msec}$; TTX, 20.2 msec). $B$, Amplitude histogram of synaptic currents in the presence of TTX is found within the control distribution but shifted to the smaller amplitude range. The number of events in TTX is much smaller than in control conditions, even though the histogram was taken from a time period twice as long as that in control (to increase events counted in TTX).

velopment in a way that differed from those of EPSCs. Spontaneous IPSCs increased in amplitude during development, due potentially to an increase in inhibitory terminals on pyramidal somata (Blanton et al., 1987; Blanton and Kriegstein, 1991b) and resulting decreased attenuation of some of the IPSCs, and due to the extreme dependence of IPSCs on AP firing, which also increased with development. AP-dependent IPSCs were significantly larger than the spontaneous IPSCs in TTX, which may correspond to the quantal IPSC size (see McLachan, 1978; Edwards et al., 1990; see also below). These TTX-insensitive IPSCs (190 $\pm 30 \mathrm{pS}$ ) had similar amplitudes to previously described quantal IPSCs in mature brain (Ropert et al., 1990: 258- 
control TTX wash

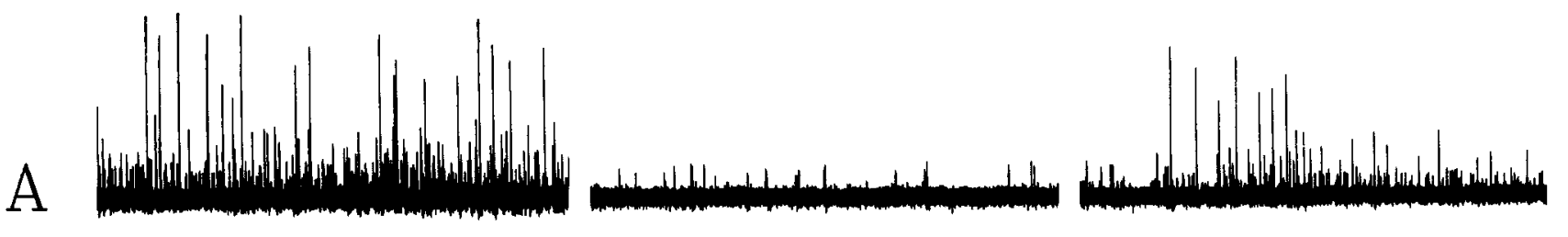

$$
\text { IPSCs }\left(\mathrm{V}_{\text {hold }}=-20 \mathrm{mV}\right)
$$

$10 \mathrm{sec}$

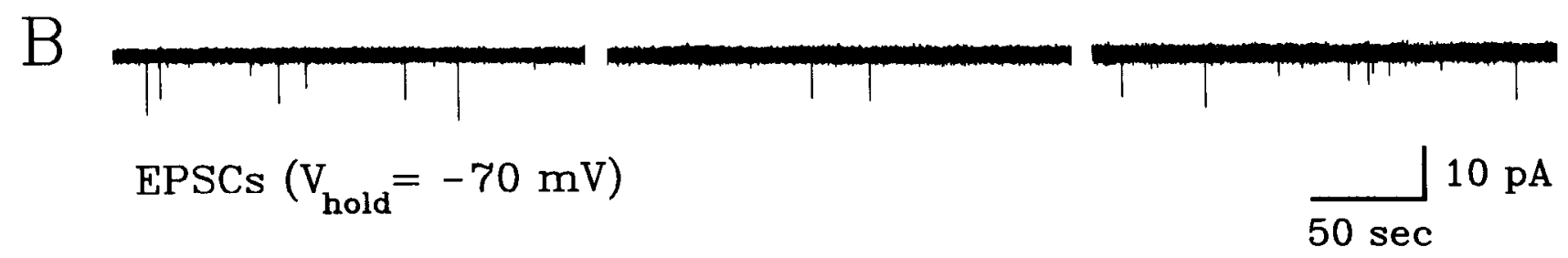

Figure 15. AP blockade produces a profound decrease in IPSC amplitude and frequency and a smaller decrease in EPSC frequency. $A$, IPSCs are reversibly decreased in amplitude and frequency by TTX in this stage $21+$ cell. $B$, EPSCs are reversibly decreased in frequency from 0.4 to 0.1 $\mathrm{Hz}$ but not noticeably in amplitude in this stage 20 cell. See Table 4 for additional detail and statistical analysis.

$326 \mathrm{pS}$; Edwards et al., 1990: 200-400 pS) as well as the early evoked IPSCs in turtles $(180 \pm 12 \mathrm{pS})$. The presence of larger cvents in the amplitude distributions of IPSCs in TTX (Fig. 14; see also for EPSCs in Fig. 9) may reflect less frequent synaptic events composed of multiple quanta.

Rise times of EPSCs and IPSCs both increased during development, but in contrast to those of EPSCs, decay time constants of IPSCs showed a decreasing trend through development. The developmental trend for decay time constants may reflect the operation of competing influences. Increases in electrotonic distance between synapses and the soma would be expected to cause an increased decay time constant, proportional to the increased rise time. The decreasing trend of decays would then reflect other mechanisms that would shorten the decay time, including altered channel open time, sensitivity, desensitization, or neuromodulation (see Moss et al., 1989; Trussel and Fischbach, 1989). Such a general decrease in time constant of decay of IPSCs occurring at the synapses may have been underestimated in thcsc rccordings, masked by dendritic electrotonic filtering that would increase both rise time and decay in a similar manner. Spontaneous IPSCs in embryos decayed monoexponentially as they do in mature animals (Ropert et al., 1990; Otis et al., 1991; LoT urco, personal communication; but see Edwards et al., 1990) and in cultured cells (Barker and Harrison, 1988).

\section{Interactions of developing excitatory and inhibitory systems}

The relative balance between excitatory and inhibitory systems is an important determinant of the nature of spontaneous activity in mature cortical circuits (Traub et al., 1987a,b). Spontaneous EPSCs were the first synaptic currents to emerge in development and showed a steady increase in frequency during the embryonic time period examined. Spontaneous IPSCs appeared relatively suddenly, long after such IPSCs could be elicited by repetitive stimulation and after inhibitory synapses are observed at the ultrastructural level (stage 18; Parnavelas, Blanton, and Kriegstein, unpublished observations). These results indicate a changing balance of synaptic drive during development.

Previous developmental studies have emphasized a slow increase in the efficacy of inhibitory function in postnatal life (Schwartzkroin, 1982; Schwartzkroin et al., 1989; Swann et al., 1989; Luhmann and Prince, 1991) based on evoked responses. No clear change in the percentage of cells with spontaneous IPSPs was noted, and the frequency of these events increased slowly (Luhmann and Prince, 1991). In the present study, in situ patch-clamp recording was performed, allowing improved resolution of small synaptic events early in development. Spontaneous IPSC activity in turtle cortex shows a sudden increase at a key developmental time point. The increase in activity of inhibitory synapses emerges at the time that recurrent collaterals of excitatory pyramidal neurons begin their elaboration at stages 20 and 21 (Blanton and Kriegstein, 1991a), with resulting increased excitatory synaptic drive on cortical circuits. The increase occurs immediately prior to the time (stage 21) at which blockade of $\mathrm{GABA}_{\mathrm{A}}$ receptors leads to spontaneous synchronized epileptiform discharges (Shen and Kriegstein, 1989). The spontaneous IPSCs may therefore function to prevent synchronized epileptic discharge (see Traub et al., 1987a,b) as well as the stabilization of excitatory synapses (Bear et al., 1987) that would reinforce the tendency for such abnormal discharges.

The developmental increase in IPSC frequency and amplitude in embryonic turtle cortex clearly depends on spontaneous AP activity, as these IPSC parameters decrease in the presence of the sodium channel blocker TTX. A similar dependence of IPSC frequency and amplitude on APs has previously been noted for mature IPSCs (Galvan et al., 1985; Edwards et al., 1990; Ropert et al., 1990; Otis et al., 1991; LoTurco, personal communication). The APs critical for increasing IPSC amplitude and fre- 


\section{embryonic stage}

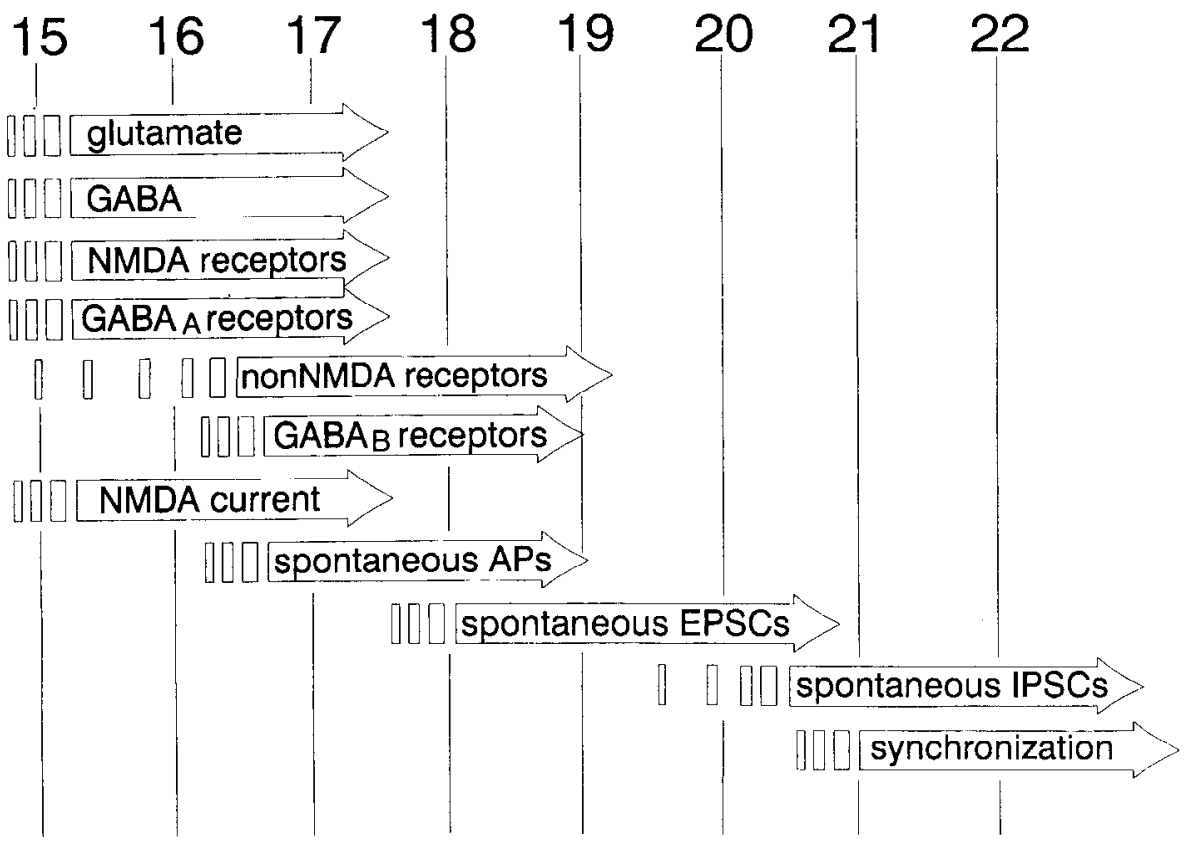

Figure 16. Summary of the development of amino acid neurotransmitterutilizing systems in the cerebral cortex of turtles. The putative neurotransmitters glutamate and GABA appear early (Blanton and Kriegstein, 1991b), along with NMDA and $\mathrm{GABA}_{\mathrm{A}}$ receptors (Blanton et al., 1990). Non-NMDA and $\mathrm{GABA}_{\mathrm{B}}$ reccptors arc detected later (Blanton and Kriegstein, unpublished observations). These receptors participate in spontaneous activity, in a characteristic sequence, beginning with NMDA receptors (Blanton et al., 1990), followed by APs, non-NMDA receptor-mediated EPSCs and later by GA$\mathrm{BA}_{\mathrm{A}}$ receptor-mediated IPSCs (this study). The spontaneous IPSCs appear suddenly late in stage 20 , just before the cortex becomes capable of synchronized epileptiform discharge when inhibition is blocked (Shen and Kriegstein, 1989).

quency could be those of pyramidal or extrinsic projection cells, whose APs and resulting EPSCs drive the nonpyramidal cells, or alternatively those of the nonpyramidal cells whose activity causes IPSCs in other cells. The effect of TTX on spontaneous IPSCs is not likely to result solely from decreased fast excitatory drive on nonpyramidal cells, because IPSCs were preserved when spontaneous EPSCs were blocked by CNQX, as has also been observed in rat hippocampus (Otis et al., 1991). Activation of nonpyramidal cells by an NMDA-mediated current (Davies and Collingridge, 1989; Sah et al., 1989) could be sufficient for maintaining IPSCs, and spontaneous NMDA-mediated currents are known to persist in CNQX and TTX (Blanton et al., 1990; LoTurco et al., 1990). However, at least in mature hippocampus, blockade of NMDA receptors does not affect IPSC frequency (Otis et al., 1991). If the relevant APs are those of nonpyramidal cells, it is of interest that the spontaneous IPSCs, while occasionally clustered (Blanton, unpublished observations), tend to have a more monotonous pattern than the repetitive AP firing of the underlying nonpyramidal cells. The relationship of presynaptic firing to transmitter release at synaptic terminals for these neurons remains to be determined.

Observations of spontaneous activity in embryonic cortex have indicated a sequence of differentiation events, in which APs appear first, followed by spontaneous EPSCs and then spontaneous IPSCs (Fig. 16). The balance of excitatory and inhibitory drive in the cortical circuit is not achieved merely by coordinating the formation of inhibitory synapses as needed to hold the excitatory circuits in check, as there is dissociation in the timing of when inhibitory synapses are first formed and when they become active. Once active, however, these inhibitory synapses may exert important influences on the rate and pattern of emergence of excitatory circuits, as indicated by the alterations in development that occur under conditions of GABA receptor blockade, both in vitro (Van Huizen et al., 1987; Desan, personal communication) and in vivo (Crabtree et al., 1983). The se- quence of appearance of AP and synaptic activity observed in this study indicates the times at which neurotransmitters, influenced by sodium-dependent AP activity and acting through GABA and glutamate receptors, may act to shape neuronal differentiation and circuit formation (Mattson, 1988; McDonald and Johnston, 1990) in the embryonic cerebral cortex.

\section{References}

Armstrong-James M (1975) The functional status and columnar organization of single cells responding to cutaneous stimulation in neonatal rat somatosensory cortex S1. J Physiol (Lond) 246:501-538.

Armstrong-James M, Caan AW, Fox K (1985) Threshold effects of $N$-methyl-D-aspartate (NMDA) and 2-amino-5-phosphonovaleric acid (2APV) on the spontaneous activity of neocortical single neurones in the urethane anesthetized rat. Exp Brain Res 60:209-213.

Aruffo C, Ferszt R, Hildebrandt AG, Cervos-Navarro J (1987) Low doses of L-monosodium glutamate promote neuronal growth and differentiation in vitro. Dev Neurosci 9:228-239.

Balázs R, Hack N, Jorgensen OS (1988) Stimulation of the $N$-methylD-aspartate receptor has a trophic effect on differentiating cerebellar granule cells. Neurosci Lett 87:80-86.

Barker JL, Harrison NL (1988) Outward rectification of inhibitory postsynaptic currents in cultured rat hippocampal neurones. J Physiol (Lond) 403:41-55.

Bear MF, Cooper LN, Ebner FF (1987) A physiological basis for a theory of synapse modification. Science 237:42-48.

Belkin DA (1963) Anoxia: tolerance in reptiles. Science 139:492-493.

Bergey GK, Fitzgerald SC, Schrier BK, Nelson PG (1981) Neuronal maturation in mammalian cell culture is dependent on spontaneous electrical activity. Brain Res 207:49-58.

Blanton MG, Kriegstein AR (1991a) Morphological differentiation of distinct neuronal classes in embryonic turtle cerebral cortex. J Comp Neurol 310:550-570.

Blanton MG, Kriegstein AR (1991b) Appearance of putative amino acid neurotransmitters during differentiation of neurons in embryonic turtle cerebral cortex. J Comp Neurol 310:571-592.

Blanton MG, Shen JM, Kriegstein AR (1987) Evidence for the inhibitory neurotransmitter gamma-aminobutyric acid in aspiny and sparsely spiny nonpyramidal neurons of turtle dorsal cortex. J Comp Neurol 259:277-297.

Blanton MG, LoTurco JJ, Kriegstein AR (1989) Whole cell recording 
from neurons in slices of reptilian and mammalian cerebral cortex. J Neurosci Methods 30:203-210.

Blanton MG, LoTurco JJ, Kriegstein AR (1990) Endogenous neurotransmitter activates $N$-methyl-D-aspartate receptors on differentiating neurons in embryonic cortex. Proc Natl Acad Sci USA 87:80278030 .

Bormann J (1988) Electrophysiology of $\mathrm{GABA}_{\mathrm{A}}$ and $\mathrm{GABA}_{\mathrm{B}}$ receptor subtypes. Trends Neurosci 11:112-116.

Brown TH, Johnston D (1983) Voltage-clamp analysis of mossy fiber synaptic input to hippocampal neurons. J Neurophysiol 50:487-507.

Chapman B, Jacobson MD, Reiter HO, Stryker MP (1986) Ocular dominance shift in kitten visual cortex caused by imbalance in retinal electrical activity. Nature 324:154-156.

Cohan CS, Kater SB (1986) Suppression of neurite elongation and growth cone motility by electrical activity. Science 232:1638-1640.

Coleman PA, Miller RF (1989) Measurement of passive membrane parameters with whole-cell recording from neurons in the intact amphibian retina. J Neurophysiol 61:218-230.

Connors BW, Gutnick MJ (1990) Intrinsic firing patterns of diverse neocortical neurons. Trends Neurosci 13:99-104.

Connors BW, Kriegstein AR (1986) Cellular physiology of the turtle visual cortex: distinctive properties of pyramidal and stellate neurons. J Neurosci 6:164-177.

Connors BW, Ransom BR (1987) Electrophysiological properties of ependymal cells (radial glia) in dorsal cortex of the turtle, Pseudemys scripta. J Physiol (Lond) 385:287-306.

Crabtree JW, Ostrach LH, Campbell BG, Chow KL (1983) Long-term effects of early cortical epileptiform activity on development of visuocortical receptive fields in the rabbit. Dev Brain Res 8:1-9.

Davies SN, Collingridge GL (1989) Role of excitatory amino acid receptors in synaptic transmission in area CAl of rat hippocampus. Proc R Soc Lond [Biol] 236:373-384

Desan PH (1988) Organization of the cerebral cortex in turtle. In: The forebrain of reptiles (Schwerdtfeger WK, Smeets WJAJ, eds), pp 111. Basel: Karger.

Dubin MW, Stark LA, Archer SM (1986) A role for action-potential activity in the development of neuronal connections in the kitten retinogeniculate pathway. J Neurosci 6:1021-1036.

Edwards FA, Konnerth A, Sakmann B (1990) Quantal analysis of inhibitory synaptic transmission in the dentate gyrus of rat hippocampal slices: a patch-clamp study. J Physiol (Lond) 430:213-249.

Forda SR, Jessell TM, Kelly JS, Rand RP (1982) Use of the patch electrode for sensitive high resolution extracellular recording. Brain Res 249:371-378.

Friauf E, McConnell SK, Shatz CJ (1990) Functional synaptic circuits in the subplate during fetal and early postnatal development of cat visual cortex. J Neurosci 10:2601-2613

Furshpan EJ, Potter DD (1989) Seizure-like activity and cellular damage in rat hippocampal ncurons in cell culturc. Neuron 3:199-207.

Galvan M, Franz P, Constanti A (1985) Spontaneous inhibitory postsynaptic potentials in guinea pig neocortex and olfactory cortex neurones. Neurosci Lett 57:131-135.

Goffinet AM (1983) The embryonic development of the cortical plate in reptiles: a comparative study in Emys orbicularis and Lacerta agilis. J Comp Neurol 215:437-452.

Goffinet AM, Daumerie C, Langerwerf B, Pieau C (1986) Neurogenesis in reptilian cortical structures: ${ }^{3} \mathrm{H}$-thymidine autoradiographic analysis. J Comp Neurol 243:106-116.

Harris WA (1981) Neural activity and development. Annu Rev Physiol 43:689-710.

Hebb DO (1949) The organization of behavior. New York: Wiley.

Hestrin S, Nicoll RA, Perkel DJ, Sah P (1990) Analysis of excitatory synaptic action in pyramidal cells using whole-cell recording from rat hippocampal slices. J Physiol (Lond) 422:203-225.

Honoré T (1989) Excitatory amino acid receptor subtypes and specific antagonists. Med Res Rev 9:1-23.

Horkiawa K, Armstrong WE (1988) A versatile means of intracellular labelling: injection of biocytin and its detection with avidin conjugates. J Neurosci Methods 25:1-11.

Huttenlocher PR (1967) Development of cortical neuronal activity in the neonatal cat. Exp Neurol 17:247-262.

Jackson MB, Lecar H, Brenneman DE, Fitzgerald S, Nelson PG (1982) Electrical development in spinal cord cell culture. J Neurosci 2:10521061.

Johnston D, Brown TH (1983) Interpretation of voltage-clamp measurements in hippocampal neurons. J Neurophysiol 50:464-486.
Konnerth A, Keller BU, Lev-Tov A (1990) Patch clamp analysis of excitatory synapses in mammalian spinal cord slices. Pfluegers Arch 417:285-290.

Kleinschmidt A, Bear MF, Singer W (1987) Blockade of "NMDA" receptors disrupts experience-dependent plasticity of kitten striate cortex. Science 238:355-358.

Kriegstein AR, Connors BW (1986) Cellular physiology of the turtle visual cortex: synaptic properties and intrinsic circuitry. J Neurosci 6:178-191.

Kriegstein AR, Suppes T, Prince DA (1987) Cellular and synaptic physiology and epileptogenesis of developing rat neocortical neurons in vitro. Dev Brain Res 34:161-171.

Kriegstein AR, Shen JM, Lee GM, Blanton MG (1988) Development of inhibitory function during corticogenesis in the turtle. In: The forebrain of reptiles (Schwerdtfeger WK, Smeets WJAJ, eds), pp 131141. Basel: Karger.

LoTurco JJ, Mody I, Kriegstein AR (1990) Differential activation of glutamate receptors by spontaneously released transmitter in slices of neocortex. Neurosci Lett 114:265-271.

LoTurco JJ, Blanton MG, Kriegstein AR (1991) Initial expression and endogenous activation of NMDA channels in early ncocortical dcvelopment. J Neurosci 11:792-799.

Luhmann HJ, Prince DA (1991) Postnatal maturation of the GABAergic system in rat neocortex. J Neurophysiol 65:247-263.

Mattson MP (1988) Neurotransmitters in the regulation of neuronal cytoarchitecture. Brain Res Rev 13:179-212.

McCormick DA, Prince DA (1987) Post-natal development of electrophysiological properties of rat cerebral cortical pyramidal neurones. J Physiol (Lond) 393:743-762.

McCormick DA, Connors BW, Lighthall JW, Prince DA (1985) Comparative electrophysiology of pyramidal and sparsely spiny stellate neurons of the neocortex. J Neurophysiol 54:782-806.

McDonald JW, Johnston MV (1990) Physiological and pathophysiological roles of excitatory amino acids during central nervous system development. Brain Res Rev 15:41-70.

McLachlan EM (1978) The statistics of transmitter release at chemical synapses. In: International review of physiology, neurophysiology III, Vol 17 (Porter R, ed), pp 49-117. Baltimore: University Park.

Michelson HB, Lothman EW (1989) An in vivo electrophysiological study of the ontogeny of excitatory and inhibitory processes in the rat hippocampus. Dev Brain Res 47:113-122.

Moss BL, Schuetze SM, Role LW (1989) Functional properties and developmental regulation of nicotinic acetylcholine receptors on embryonic chicken sympathetic neurons. Neuron 3:597-607.

Mountcastle VB, Talbot WH, Sakata H, Hyvarinen J (1969) Cortical neuronal mechanisms in flutter-vibration studied in unanesthetized monkeys. Neuronal periodicity and frequency discrimination. $\mathbf{J} \mathrm{Neu}-$ rophysiol 32:452-484.

Nelson PG, Yu C, Ficlds RD, Ncalc EA (1989) Synaptic connections in vitro: modulation of number and efficacy by electrical activity. Science 244:585-587.

Otis TS, Staley KJ, Mody I (1991) Perpetual inhibitory activity in mammalian brain slices generated by spontaneous GABA release. Brain Res 545:142-150.

Pearce IA, Cambray-Deakin MA, Burgoyne RD (1987) Glutamate acting on NMDA receptors stimulates neurite outgrowth from cerebellar granule cells. FEBS Lett 223:143-147.

Prince DA, Huguenard JR (1988) Functional properties of neocortical neurons. In: Neurobiology of neocortex (Rakic P, Singer W, eds), pp 153-176. New York: Wiley.

Prince DA, Kriegstein AR (1989) Electrophysiologic studies of immature neocortical neurons. In: Problems and concepts in developmental ncurophysiology (Kellaway P, Noebels JL, eds), pp 198-211. Baltimore: Johns Hopkins UP.

Rall W (1977) Core conductor theory and cable properties of neurons. In: Handbook of physiology. The nervous system. Cellular biology of neurons (Brookhart JM, Mountcastle VB, eds), pp 39-96. Bethesda: American Physiological Society.

Rall W, Segev I (1985) Space-clamp problems when voltage clamping branched neurons with intracellular microelectrodes. In: Voltage and patch clamping with microelectrodes (Smith TG Jr, Lecar H, Redman SJ, Gage P, eds), pp 191-215. Bethesda: American Physiological Society.

Reh TA, Constantine-Paton M (1985) Eye-specific segregation requires neural activity in three-eyed Rana pipiens. J Neurosci 5:11321143. 
Ropert N, Miles R, Korn H (1990) Characteristics of miniature inhibitory postsynaptic currents in CAl pyramidal neurones of rat hippocampus. J Physiol (Lond) 428:707-722.

Sah P, Hestrin S, Nicoll RA (1989) Tonic activation of NMDA receptors by ambient glutamate enhances excitability of neurons. Science 246:815-818.

Sah P, Hestrin S, Nicoll RA (1990) Properties of excitatory postsynaptic currents recorded in vitro from rat hippocampal interneurones. J Physiol (Lond) 430:605-616.

Schwartzkroin PA (1982) Development of rabbit hippocampus: physiology. Dev Brain Res 2:469-486.

Schwartzkroin PA, Kunkel DD, Mueller AL, Haglund MM (1989) The developmental electrophysiology of the rabbit hippocampus. In: Problems and concepts in developmental neurophysiology (Kellaway P, Noebels JL, eus), pp 225-246. Ballimure: Juhns Hopkins UP.

Segal MM, Furshpan EJ (1990) Epileptiform activity in microcultures containing small numbers of hippocampal neurons. J Neurophysiol 64:1390-1399.

Shatz CJ (1990) Competitive interactions between retinal ganglion cells during prenatal development. J Neurobiol 21:197-211.

Shatz CJ, Stryker MP (1988) Prenatal tetrodotoxin infusion blocks segregation of retinogeniculate afferents. Science 242:87-89.

Shen JM, Kriegstein AR (1989) The development of bicuculline-induced epileptiform discharges in embryonic turtle cortex. Neurosci Lett 98:184-188.

Smith TG Jr, Lecar H, Redman SJ, Gage PW (1985) Voltage and patch clamping with microelectrodes. Bethesda: American Physiological Society.

Sommer B, Keinanen K, Verdoom TA, Wisden W, Burnashev N, Herb A, Köhler M, Takagi T, Sakmann B, Seeburg PH (1990) Flip and flop: a cell-specific functional switch in glutamate-operated channels of the CNS. Science 249:1580-1585.

Stent GS (1973) A physiological mechanism for Hebb's postulate of learning. Proc Natl Acad Sci USA 70:997-1001.
Stryker MP (1989) Evidence for a possible role of spontaneous electrical activity in the development of the mammalian visual cortex. In: Problems and concepts in developmental neurophysiology (Kellaway P, Noebels JL, eds), pp 110-130. Baltimore: Johns Hopkins UP.

Sur M, Pallas SL, Roe AW (1990) Cross-modal plasticity in cortical development: differentiation and specification of sensory neocortex Trends Neurosci 13:227-233.

Swann JW, Brady RI, Martin DL (1989) Postnatal development of GABA-mediated synaptic inhibition in rat hippocampus. Neuroscience 28:551-561.

Traub RD, Miles R, Wong RKS (1987a) Models of synchronized hippocampal bursts in the presence of inhibition. I. Single population events. J Neurophysiol 58:739-751.

Traub RD, Miles R, Wong RKS, Schulman LS, Schneiderman JH (1987b) Models of synchronized hippocampal bursts in the presence of inhibition. II. Ongoing spontaneous population events. J Neurophysiol 58:752-764.

Trussell LO, Fischbach GD (1989) Glutamate receptor desensitization and its role in synaptic transmission. Neuron 3:209-218.

Van Huizen F, Romijn HJ, Habets AMMC, Van den Hooff P (1987) Accelerated neuron network formation in rat cerebral cortex cultures chronically disinhibited with picrotoxin. Exp Neurol 97:280-288.

Westbrook GL, Brenneman DE (1984) The development of spontaneous electrical activity in spinal cord cultures. In: Developmental neuroscience: physiological, pharmacological and clinical aspects $(\mathrm{Ca}-$ ciagli F, Giacobine E, Paolette R, eds), pp 11-17. Amsterdam: Elsevier.

Wilson AM, Desan PH, Kriegstein AR (1988) Development of the turtle cerebral cortex in vitro. Soc Neurosci Abstr 14:92.

Yntema C (1968) A series of stages in the embryonic development of Chelydra serpentina. J Morphol 125:219-252. 